Revised version submitted to 'Geomechanics for Energy and the Environment' Special Issue on 'Selected papers Symposium on Energy Geotechnics 2015'

\title{
STUDYING THE THERMAL CONDUCTIVITY OF A DEEP EOCENE CLAY FORMATION: DIRECT MEASUREMENTS VS BACK-ANALYSIS RESULTS
}

Enrique Romero ${ }^{1 *}$, Nuria Sau ${ }^{1}$, Analice Lima $^{2}$, Hervé Van Baelen $^{3}$, Xavier Sillen ${ }^{3}$ and Xiangling $\mathrm{Li}^{4}$

\section{Affiliation:}

1 Division of Geotechnical Engineering and Geosciences, Department of Civil and Environmental Engineering, Universitat Politècnica de Catalunya, c/ Jordi Girona 1-3, Campus Nord UPC, Building D-2, 08034 Barcelona, Spain

2 Universidade Federal de Pernambuco, Av. Prof. Moraes Rego, 1235, Cidade Universitária, Recife, Brazil

3 ONDRAF/NIRAS, Belgian Agency for Radioactive Waste and Enriched Fissile Materials, Avenue des Arts 14, 1210 Brussels, Belgium

${ }^{4}$ EIG EURIDICE, European Underground Research Infrastructure for Disposal of nuclear waste In Clay Environment, Boeretang 200, 2400 Mol, Belgium

\section{* Contact details:}

Prof. Enrique Romero

Division of Geotechnical Engineering and Geosciences, Department of Civil and Environmental Engineering, Universitat Politècnica de Catalunya, c/ Jordi Girona 1-3, Campus Nord, Building D-2, 08034 - Barcelona - Spain

Fax: +34-93 4017251

e-mail: enrique.romero-morales@upc.edu

Number of words in the main text: 6415

Number of tables: 7

Number of illustrations: 13 


\section{Highlights:}

- Pre-conditioning protocols before thermal conductivity tests on a deep clay formation

- Anisotropic features on thermal conductivity

- Finite element program to calibrate by back-analysis some soil thermal properties

- Consistency of direct measurements with back-analysis results 


\begin{abstract}
An experimental study on Ypresian clays - one of the potential deep and sedimentary clay formations in Belgium for the geological disposal of heat-emitting radioactive waste - has been undertaken to systematically study its thermal conductivity using different experimental techniques. As a first step, a new experimental setup with heat flux measurement has been used and careful pre-conditioning protocols have been followed to directly measure this thermal property. The aim of these pre-conditioning tests has been ensuring a very high degree of saturation and the closure of fissures / gaps along bedding planes before the thermal tests are run under low stress conditions. Thermal tests have shown to be particularly sensitive when the thermal conductivity is determined along a direction orthogonal to these bedding planes. The study is then complemented by using a constant volume heating cell, in which heating pulse tests have been carried out under fully saturated conditions that have been ensured with a high water back-pressure. Numerical models have been used to interpret this pulse test, to exploit all the information provided by temperature measurements and to back-analyse the thermal conductivity. Direct thermal conductivity data with the improved pre-conditioning protocol allowed obtaining results consistent with the values reported when using back-analysis in the constant volume cell. The article discusses the importance of restoring full saturation conditions, particularly on retrieval of deep sedimentary clays, which may undergo opening of fissures along bedding planes that may affect the correct determination of the thermal conductivity.
\end{abstract}

Keywords: deep sedimentary clay; thermal conductivity; thermal conductivity setup; heating cell; back-analysis thermal properties 


\section{Introduction}

The thermal conductivity of soils and rocks $(\lambda)$ is becoming increasingly important due to the rise of new applications in energy geotechnics, particularly in the design of energy geo-structures, energy geo-storage and deep geological disposal of heat-emitting and long-lived radioactive waste (see for instance, $[1,2,3,4]$ ).

In the case of radioactive waste repositories, the possibility of disposal facilities is currently considered in deep sedimentary argillaceous host formations (Boom Clay / Ypresian clays, Opalinus Clay and Callovo-Oxfordian Clay for the Belgian, Swiss and French potential host rocks, respectively). A characterisation of the thermal properties is required for determining the evolution of the near field temperature in the host formation around disposal galleries, as they may affect the design and layout of the repository. It is also required for assessing the perturbations that the system will undergo resulting from temperature changes over hundreds to thousands of years after waste emplacement [5]. To deal with the thermal characterisation of these clay deposits, small scale in situ heating tests have been usually used to determine the thermal conductivity by back-analysis (see for instance, Refs. [6, 7]). The interpretation of these tests allowed detecting a clear influence of the bedding planes on the anisotropic heat conduction properties of these sedimentary clays with bedding fabric resulting from the initial deposition and further geological processes. The anisotropy in terms of thermal conductivity arises as a combination of different factors, such as the mineralogical variation in sedimentary layering, the anisotropy of thermal properties of clay minerals, the alignment of particles with possibly anisotropy of grain-to-grain contacts and the preferential orientation of fissures. Nevertheless, as reported by Ref. [7], the back-analysis methodology is not free of drawbacks, since a certain degree of judgment must be always put in interpreting the large amount of in situ data recorded, particularly when dealing with uncertainties of temperature sensor locations, power loss and specific heat properties.

Alternatively, laboratory tests on well preserved samples have been preferred for deeper depths - where in situ tests have not been performed - or when dealing with specific effects on thermal conductivity under better controlled conditions. Recently, Refs. [8, 9] studied the thermal conductivity of Boom Clay (retrieved from HADES Underground Research Laboratory at Mol, Belgium, at a depth of $223 \mathrm{~m}$ ) with a needle thermal probe 
technique at different orientations with respect to the bedding planes. Despite the apparent simplicity and standardisation of the experimental setup used, it is important to highlight that exploring thermal conductivity features on this type of sedimentary rocks with bedding planes is not straightforward. One of the main drawbacks when laboratory tests are performed under low stress conditions refers to the possibility of opening of fissures and gaps along bedding planes that affect the correct determination of the thermal conductivity. This can be observed in Table 1, which collects recent thermal conductivity results on Boom Clay at two different orientations using different methodologies (backanalysis of in situ and laboratory tests and direct measurements in laboratory). In the table, $\lambda / /$ is the thermal conductivity for heat flow parallel to bedding planes, $\lambda_{\perp}$ the thermal conductivity for heat flow orthogonal to bedding planes and $\eta_{T}$ the thermal conductivity anisotropy ratio $\left(\eta_{T}=\lambda_{/ /} / \lambda_{\perp}\right)$. As shown in Table 1 , and besides differences in the temperature of the clay, values of $\lambda / /$ are quite similar (average value around $1.6 \mathrm{Wm}^{-1} \mathrm{~K}^{-1}$ ). Nevertheless, values of $\lambda_{\perp}$ display a larger variability, associated with additional effects besides the temperature of the medium. Back-analysed data from in situ tests tend to indicate higher values of $\lambda_{\perp}$ than those reported with small-scale laboratory experiments, particularly when samples present degrees of saturations $S_{r}<1$ as a consequence of the aperture of bedding planes after the important stress relief undergone during retrieval. A similar behaviour has been also detected on retrieved cores of deeper samples of Ypresian clays (Doel, Belgium). I.N.I.S.Ma [10] studied the thermal conductivity $\lambda_{\perp}$ of this Belgian potential host rock at depths between 340 and 400 m using a thermal conductivity tester under low vertical stress and lateral unconfined conditions. Their study indicated relatively low values between 0.62 and $1.12 \mathrm{Wm}^{-1} \mathrm{~K}^{-1}$ at $(370 \pm 8) \mathrm{m}$, despite the high quartz content of this material (between $24 \%$ and $45 \%$ for equivalent stratigraphic levels $[11,12])$.

One of the objectives of the present paper is to give confidence on the measured data of thermal conductivity of deep sedimentary clays in the laboratory, as well as to highlight the importance of restoring full saturation. To this end, two procedures have been followed in the current research on cores of Ypresian clays retrieved at a depth around $370 \mathrm{~m}$. The first uses a new experimental setup with heater and heat flux measurement on top and bottom caps, in which the thermal conductivity on two different orientations (heat flow parallel and perpendicular to bedding planes) have been explored. Since the 
setup uses a low confining stress, a careful pre-conditioning protocol has been followed on the retrieved samples before measuring their thermal conductivity. The aim of these pre-conditioning tests that have been run on a high-pressure isotropic cell has been to ensure a very high degree of saturation at in situ stress conditions and the consequent closure of fissures / gaps along bedding planes before performing the thermal tests. The second procedure has been followed on an axi-symmetric and constant volume heating cell, in which heating pulse tests have been carried out under fully saturated conditions with a high water back-pressure applied. Attention is focused on the time evolution of temperature along heating and cooling paths. A finite element program was used to determine the saturated thermal conductivity by back-analysis and then to simulate selected experimental results.

\section{Material tested}

Tests have been carried out on deep Ypresian clays - one of the potential Belgian host formations for disposal of high-level radioactive wastes - which are constituted by marine sediments deposited during the Ypresian Age (oldest age of the Eocene Epoch spanning the time between 56 and 47.8 Ma). Ypresian clays at Kallo (Belgium) are located between 300 and $450 \mathrm{~m}$ depth, and sample cores have been retrieved at $370 \mathrm{~m}$ (cores \#83 and \#84). Close to this retrieval depth, the clay formation presents around 44 to $57 \%$ of clay minerals, which are dominated by smectite (64 to 66\%) and illite-smectite (24\%). Nonclayey fraction is constituted predominantly by quartz (37 to $43 \%$ ) and plagioclase (4 to $6 \%)[11,12]$. Table 2 summarises the geotechnical characterisation, as well as volumetric and gravimetric properties of the studied cores. As observed in the table, some anisotropy in terms of water permeability has been detected $[15,16]$.

The Ypresian clays at the depth of interest display bimodal pore size density functions obtained with mercury intrusion porosimetry on freeze-dried samples and with dominant entrance pore modes at $700 \mathrm{~nm}$ and $80 \mathrm{~nm}$ (valley between peaks at around $300 \mathrm{~nm}$ ) [15, 16]. The smallest pore sizes (micropores with sizes $<300 \mathrm{~nm}$ ) can be associated with pores inside the argillaceous rock matrix (clayey paste that hosts quartz and plagioclase), which account for a microporosity around $n_{m}=0.32$ (between $70 \%$ and $76 \%$ of the total one). The largest pores are related to macropores and fissures (see for instance Ref. [18] 
for an equivalent separation of the pore domains in Boom Clay). I.N.I.S.Ma [10] reported a microporosity (pore sizes $<30 \mathrm{~nm}$ ) around 0.17 at the depth of interest.

The in situ condition at the sampling depth can be characterised by a vertical total stress $\sigma_{v i}=7.4 \mathrm{MPa}$ and an estimated water pressure around $u_{w i}=3.7 \mathrm{MPa}$ (vertical effective stress $\sigma_{v i}^{\prime}=3.7 \mathrm{MPa}$ ). Lima [15] and [16, 19] reported a yield vertical effective stress around $\sigma_{v y}^{\prime}=5.5 \mathrm{MPa}$, which results in a yield stress ratio $Y S R=\sigma_{v y}^{\prime} / \sigma_{v i}^{\prime} \approx 1.5$. An earth pressure coefficient at rest $K_{0}^{S C}=\left(1-\sin \phi^{\prime}\right) \sqrt{Y S R} \approx 0.9$ can be estimated considering $\phi^{\prime}=16^{\circ}[20]$, which allows determining the mean total stress at in situ condition $p_{i}=$ $p_{i}^{\prime}+u_{w i}=7.1 \mathrm{MPa}$ (where $p_{i}^{\prime}=\left[\left(1+2 K_{0}^{S C}\right) / 3\right] \sigma_{v i}^{\prime}=3.4 \mathrm{MPa}$ is the mean effective stress). If perfect sampling is assumed (no mechanical disturbances during sampling, transportation, storage and extrusion / trimming), the release of total vertical and horizontal stresses $\left(\Delta \sigma_{v}=-\sigma_{v i}=-7.4 \mathrm{MPa} ; \Delta \sigma_{h}=-\left(K_{0}^{S C} \sigma_{v i}^{\prime}+u_{w i}\right)=-7.0 \mathrm{MPa}\right)$ induces a change in pore water pressure $\Delta u_{w}=B\left[\Delta \sigma_{h}+A\left(\Delta \sigma_{v}-\Delta \sigma_{h}\right)\right]$. For saturated conditions $(B=1)$ and assuming perfect elastic / isotropic material $(A=1 / 3)$ - consistent with the lightly overconsolidated state - the decrease of pore water pressure is equal to the decrease of mean total stress during undrained sample retrieval $\Delta u_{w}=\Delta p=-7.1 \mathrm{MPa}$. A final pore water pressure of $u_{w f}=-3.4 \mathrm{MPa}$ after retrieval is obtained, which should be compared with the lower as-retrieved matric suctions reported in Table 2 (between 1.4 and $2.1 \mathrm{MPa}$, after considering the osmotic component). The large matric suction induced on retrieval cannot be sustained under saturated conditions due to the relatively low air-entry value of the material associated with the largest pore mode (air-entry value around $0.4 \mathrm{MPa}$ for $700 \mathrm{~nm}$ ). As a consequence and despite the careful sampling and trimming, some air is expected to enter the soil during retrieval, which induces the degree of saturation to decrease (refer to Table 2) and fissures / gaps along bedding planes to open.

Johansen [21] proposed a simplified version of the geometric mean method for the assessment of the thermal conductivity of solid particles $\lambda_{s}\left(\right.$ in $\mathrm{Wm}^{-1} \mathrm{~K}^{-1}$ ) with dominant quartz content (quartz content $q>0.20$ ): $\lambda_{s}=7.7^{q} \cdot 2.0^{(1-q)}$. This author considered a thermal conductivity of $7.7 \mathrm{Wm}^{-1} \mathrm{~K}^{-1}$ for quartz and a lower value of $2.0 \mathrm{Wm}^{-1} \mathrm{~K}^{-1}$ for the remaining rock-forming minerals [22]. An average quartz content $q=0.40$ for Ypresian 
clays at the depth of interest has been considered, which results in $\lambda_{s}=3.43 \mathrm{Wm}^{-1} \mathrm{~K}^{-1}$. An estimation of the saturated thermal conductivity of the argillaceous rock matrix can be done based on the geometric mean method [23], and considering the thermal conductivity of the liquid phase as the combination of adsorbed and free water due to the mineralogical properties of the clay (dominated by smectite and illite-smectite, and with a specific surface around $60 \mathrm{~m}^{2} / \mathrm{g}$ measured with nitrogen adsorption at the depth of interest [10]). The argillaceous rock matrix may be described as a dense clayey paste that hosts rock forming minerals such as quartz and plagioclase and that presents a microporosity $n_{m}=0.32$. A liquid phase thermal conductivity inside the rock matrix of $\lambda_{w m}=0.80 \mathrm{Wm}^{-}$ ${ }^{1} \mathrm{~K}^{-1}\left(33 \%\right.$ higher than free water $0.60 \mathrm{Wm}^{-1} \mathrm{~K}^{-1}$ at $\left.20^{\circ} \mathrm{C}\right)$ can be accepted (adsorbed monolayer water can be around 2 to $3 \mathrm{Wm}^{-1} \mathrm{~K}^{-1}$, according to Ref. [24]). This way, an expected saturated $\lambda_{\text {sat } m}$ of the rock matrix would be

$$
\lambda_{\text {sat } m}=\lambda_{s}^{\left(1-\mathrm{n}_{m}\right)} \lambda_{w m}^{\mathrm{n}_{m}}=3.43^{0.68} \times 0.80^{0.32}=2.2 \mathrm{Wm}^{-1} \mathrm{~K}^{-1}
$$

Table 2 also includes for comparison the characterisation and properties of Boom Clay $[18,17]$ taken at a depth of $221 \mathrm{~m}$ from URL HADES (Mol, Belgium). Boom Clay (located at a depth between 160 and $270 \mathrm{~m}$ at Mol site) is another Belgian potential host formation for disposal of high-level radioactive wastes, which has been the objective of extensive research programmes and as a consequence has been better characterised. This clay has been used in the preliminary thermal conductivity testing programme described in section 3.3 .

\section{Experimental programme for thermal conductivity measurement}

\subsection{Pre-conditioning of samples before thermal tests}

As highlighted above, retrieved samples should be pre-conditioned to ensure a higher degree of saturation and the closure of already opened fissures and gaps along bedding planes before performing the thermal tests, which were run under relatively low stresses (compared to in situ stresses).

A total of nine samples were tested, which are listed in Table 3. Two pre-conditioning protocols (Pr-1 and Pr-2 in Table 3) were followed on seven samples before the thermal 
tests. The remaining samples were tested under as-retrieved conditions without preconditioning protocols (W/P in Table 3). A high-pressure isotropic cell with axial and radial displacement transducers was used to apply the isotropic stress paths. Axial displacements were measured with an external LVDT, whereas radial displacements were registered with two opposite electro-optical laser systems placed outside the cell [25]. Along protocol Pr-1 the sample was isotropically loaded at constant water content and controlled stress rate $(38 \mathrm{kPa} / \mathrm{min})$ to a total mean stress $p=3.5 \mathrm{MPa}$ (equivalent to in situ mean effective stress). The initial suction was expected to vanish during this water undrained loading process. Afterwards, the specimen was unloaded at a faster rate (76 $\mathrm{kPa} / \mathrm{min}$ ) keeping both top and bottom drainage lines closed. Despite the closure of valves, it was anticipated that some air (trapped in the upper and bottom drainage lines) could enter the soil during this matric suction increase path and thus reduce the high degree of saturation previously attained on loading. Protocol Pr-2 was therefore preferred with the aim of improving the previous one. Along this second protocol, which follows the same isotropic loading path to $p=3.5 \mathrm{MPa}$ and at the same stress rate, the top and bottom lines were filled with synthetic Ypresian clay water before their closure during the fast and water undrained unloading path. Despite the increase in matric suction during this unloading path, air was not allowed to enter and a higher degree of saturation was expected closer to the one reached at the final stage of the loading path.

\subsection{Experimental setup}

A steady-state method based on the setup described in Ref. [26] was adopted to perform the thermal tests under relatively low stresses [27]. It was designed to apply a high temperature (around $54^{\circ} \mathrm{C}$ ) at the top of a cylindrical specimen $(38 \mathrm{~mm}$ in diameter and $40 \mathrm{~mm}$ high) and to maintain the bottom end at a value close to $30^{\circ} \mathrm{C}$ (room temperature was kept at around $20^{\circ} \mathrm{C}$ ). Top and bottom temperatures were regulated using thermostats that switched electrical resistances off at the desired setpoint based on values measured by thermocouples placed inside top and bottom caps. Figure 1 presents a cross-section and a set of pictures of the different components of the setup. Two heat flux sensors with reference material ( $1 \mathrm{~mm}$ polycarbonate disc with $\lambda_{\text {poly }}=0.20 \mathrm{Wm}^{-1} \mathrm{~K}^{-1}$ between two 3 $\mathrm{mm}$ aluminium discs with $\lambda_{\text {alu }}=209 \mathrm{Wm}^{-1} \mathrm{~K}^{-1}$ ) were used. As shown in the picture, small holes were drilled into the aluminium discs. Thermocouples were then inserted to 
measure the temperature (measuring points $\mathrm{T}_{1}, \mathrm{~T}_{2}, \mathrm{~T}_{6}$ and $\mathrm{T}_{7}$ in Figure 1$)$. Inflow, $q_{\text {in }}\left(\mathrm{Wm}^{-}\right.$ ${ }^{2}$ ), and outflow, qout $\left(\mathrm{Wm}^{-2}\right)$, heat fluxes were determined as

$$
q_{\text {in }}=\frac{\lambda_{\text {poly }} \Delta T_{\text {top }}}{t_{\text {disc }}} \text { and } q_{\text {out }}=\frac{\lambda_{\text {poly }} \Delta T_{\text {bot }}}{t_{\text {disc }}}
$$

where $\Delta T_{\text {top }}$ and $\Delta T_{b o t}$ are the temperature changes between aluminium discs on both top and bottom caps, and $t_{\text {disc }}=1 \mathrm{~mm}$ is the height of the polycarbonate disc. This expression assumes negligible thermal gradient in the aluminium discs as a consequence of the high $\lambda_{a l u}$ (i.e., no temperature difference between measuring points and the contact surface with polycarbonate).

An additional external layer of heat insulating foam (polyisocyanurate foam) was placed around the sample with neoprene membrane to limit lateral loss of heat (Figure 1). Any difference in heat flux measurements between top and bottom caps represented heat loss from the sample. The use of the neoprene membrane allowed soil deformation while keeping constant water content. Contact errors between the sample and heat flux sensors were minimised by coating the sample surface with thermal grease. To further enhance the contact between thermal caps and the sample, the whole setup was axially loaded. Temperature evolutions in the heat flux sensors (four thermocouples) and at three internal points of the sample - located at regular intervals - were continuously monitored. Figure 1 indicates the position of the different thermocouples.

Three small-diameter holes $(<1 \mathrm{~mm})$ were carefully drilled in the sample and then filled with thermal grease for the installation of thermocouples. Before the thermal test, electric resistances were switched on and top and bottom caps were heated. Afterwards, the soil sample was installed in the thermal conductivity setup, and a vertical load applied to ensure better contact between caps and sample. Tests were performed with an average specimen temperature close to $43^{\circ} \mathrm{C}$, with a temperature difference $\Delta T$ along the sample height around $20^{\circ} \mathrm{C}$.

When applying temperature controlled conditions at the boundaries of the specimen to induce the thermal gradient, indirect processes arising as a consequence of this primary gradient evolved independently from any external control (moisture re-distribution and local soil volume changes). The temperature range applied ensured an adequate gradient 
for the tests, while keeping the effects of temperature dependence on thermal conductivity, as well as those arising from moisture re-distribution and local soil volume changes, as low as possible. Water contents and dry densities were measured at different heights of the sample after the thermal tests (final water contents and void ratios were slightly lower close to the top cap at high temperature).

\subsection{Preliminary thermal conductivity tests}

Several preliminary tests were performed to increase the know-how of the setup and to study the response of statically compacted Ypresian clay at different degrees of saturation. Figure 2 shows two thermal test results performed at two different vertical stresses (265 $\mathrm{kPa}$ and $370 \mathrm{kPa}$ ) on statically compacted Ypresian clay samples (void ratio $e=0.80$ and degree of saturation $S_{r}=1$ ). The figure shows the time evolution of the difference between inflow $q_{\text {in }}$ and outflow $q_{\text {out }}$ heat fluxes referred to $q_{\text {in }}\left(\Delta q / q_{i n}\right.$, a measure of heat losses of the system). As observed, the system is very sensitive to vertical stress. All tests were performed at a vertical stress of $370 \mathrm{kPa}$ to ensure better contact between caps and sample, as well as to limit $\Delta q / q_{\text {in }} \leq 0.05$ under steady-state conditions (usually at $t>2500 \mathrm{~s}$ ).

To study the dependence between $\lambda$ and $S_{r}$ in Ypresian clays, a set of thermal conductivity tests were performed on statically compacted Ypresian clay samples at the same void ratio $e=0.80$ - close to in situ conditions - and at different degrees of saturations (see Table 4). Despite the different microstructure (pore size distribution) generated on compaction compared to the natural state, the study allows highlighting the important effect of losing full saturation during sample retrieval. Table 4 and Figure 3 summarise the results for different degrees of saturation. Figure 3 also includes the ratio $\lambda / \lambda_{\text {sat }}$ with $S_{r}$ predicted by the geometric mean model (see for instance, Ref. [23]), which is based on the following expression

$$
\begin{aligned}
& \lambda=\lambda_{s a t}^{S_{r}} \lambda_{d r y}^{\left(1-S_{r}\right)} ; \lambda_{s a t}=\lambda_{s}^{(1-n)} \lambda_{w}^{n} ; \lambda_{d r y}=\lambda_{s}^{(1-n)} \lambda_{a}^{n} \\
& \frac{\lambda_{\text {sat }}}{\lambda_{d r y}}=\left(\frac{\lambda_{w}}{\lambda_{a}}\right)^{n}=A^{n} \text { and } \frac{\lambda}{\lambda_{s a t}}=A^{-n\left(1-S_{r}\right)}
\end{aligned}
$$


where ' $s$ ', ' $w$ ' and ' $a$ ' subscripts stand for solid, water and air, respectively, $n$ is the porosity and $S_{r}$ the degree of saturation. A value of $A=30$ has been fitted for $n=0.44$, which is associated with $\lambda_{w}=0.78 \mathrm{Wm}^{-1} \mathrm{~K}^{-1}$ (close to the value used in Eq.(1)) for $\lambda_{a}=0.026 \mathrm{Wm}^{-1} \mathrm{~K}^{-1}$ at $20^{\circ} \mathrm{C}$.

The thermal conductivity of two natural Boom Clay samples without pre-conditioning on two different orientations (heat flow parallel and perpendicular to bedding planes at an average specimen temperature close to $43^{\circ} \mathrm{C}$ ) was also studied to build confidence in the experimental setup. This reference clay has been widely studied, as shown in the compilation presented in Table 1. The sample (core 8) used in the present study was taken from a horizontal borehole (R66-67W) located at a depth of $221 \mathrm{~m}$ in the Mol site (HADES Underground Laboratory in Belgium). Table 2 shows the characterisation and properties of the material, which displays a fully saturated condition and thus justifies the decision made for not performing the pre-conditioning paths. Table 1 presents these thermal conductivity results together with the anisotropy ratio compared to recent published data, in which a good agreement is obtained, particularly with results from back-analyses at $S_{r}=1$.

\subsection{Experimental results: pre-conditioning paths and thermal conductivity}

Figure 4 shows the loading and unloading pre-conditioning paths in terms of volumetric strain and degree of saturation changes of two Ypresian clay specimens that follow protocol Pr-2: Y3-N (core axis orthogonal to bedding planes) and Y2-P (core axis parallel to bedding planes). Probably more alteration has been induced on the extraction of specimen Y2-P, which presented a lower initial degree of saturation. During isotropic loading at constant water content ( $\mathrm{AB}$ in Figure 4), specimen $\mathrm{Y} 3-\mathrm{N}$ reached full saturation at point $\mathrm{B}$. After attaining point $\mathrm{B}$, the specimen was further loaded to point $\mathrm{C}$ and then allowed equilibrating to dissipate any excess pore pressure at $p=3.5 \mathrm{MPa}$ before filling the top and bottom lines with synthetic Ypresian clay water (properties of this synthetic water are presented in Table 2). During the unloading path DE, the sample underwent some small expansion and some desaturation (estimated based on the assumption of constant water content during unloading). A maximum volumetric deformation of $2.10 \%$ (positive in compression) was attained by sample Y3-N on loading, which corresponded to a void ratio change $\Delta e=-0.037$ and induced $S_{r}$ to increase to 1. Sample Y2-P 
underwent a larger compression of $4.37 \%$, with a corresponding $\Delta e=-0.077$ at a final $S_{r}=1$. Table 5 summarises all the results from the loading-unloading pre-conditioning paths Pr-1 and Pr-2. It is not easy however to indicate which protocol was best suited to ensure a higher degree of saturation, since only two tests were performed with Pr- 1 . Nevertheless, protocol Pr-2 was preferred, since it was expected a better preservation of the degree of saturation attained on loading (results reported in the table seem to indicate this fact with somewhat lower average expansion during unloading).

Figures $5 \mathrm{a}$ and $5 \mathrm{~b}$ display the time evolutions of temperature (seven thermocouples) during the thermal tests on Y2-P and Y3-N, respectively. Elapsed time started after finishing the experimental installation and samples already underwent some heating during this setting-up stage. The use of the transient stage for the determination of specific heat properties is out of the scope of the present paper. As observed in the figure, the thermal conductivity is not constant along the sample height, since temperature differences at steady-state conditions between points (supposed equidistant) are not constant. Different phenomena contribute to these changes associated with local soil volume changes (tested samples display a slight decrease of void ratio towards the upper part of the sample), with water content re-distribution (final water contents slightly lower close to the top cap at high temperature), with some temperature effects on the thermal conductivity, and with spurious experimental problems (distances between measuring points that are not constant, interface problems across the contacts between sample and caps). Temperature dependence of thermal conductivity (mainly associated with its dependence on quartz and water) is expected not to greatly affect the measured values within the temperature range used. In this temperature range, the decrease in thermal conductivity of quartz with increase in temperature is around $-0.0235 \mathrm{Wm}^{-1} \mathrm{~K}^{-1} / \mathrm{K}$ [28] and the increase in thermal conductivity of water around $0.0015 \mathrm{Wm}^{-1} \mathrm{~K}^{-1} / \mathrm{K}$, which compensates the temperature sensitivity of clay thermal conductivity.

The time evolutions of inflow and outflow heat fluxes (Eq. (2)) are plotted in Figure 6 for these two samples. Normalised heat losses $\Delta q / q_{\text {in }}$ are also indicated in the figure tending to $<5 \%$ under steady-state conditions, which is approximately reached at elapsed times larger than $2500 \mathrm{~s}$. The evolution of $q_{a v e} L / \Delta T$ with elapsed time ( $\left.t>2500 \mathrm{~s}\right)$ for the different tests performed is plotted in Figure 7. qave represents the average inflow and outflow heat fluxes and $\Delta T$ has been estimated using $T_{2}$ and $T_{6}$ ( $L$ is the sample height). Under steady-state conditions, these plotted values represent the global (average) thermal 
conductivity at two different orientations of the heat flow (orthogonal and parallel to bedding planes). Table 6 summarises these thermal conductivity results including the degrees of saturation before the thermal tests, as well as the average final water contents after the experiments together with final water contents at top and bottom positions of the different samples (final water contents were systematically lower close to the top cap at high temperature). Thermal conductivity results include the deviations associated with these water content changes.

Figure 8 plots the influence of the initial degrees of saturation on the thermal conductivity. As shown, samples without pre-conditioning (W/P) and with protocol Pr-1 display thermal conductivity values lower than samples pre-conditioned following protocol Pr-2, highlighting the role played by the degree of saturation before the thermal tests. The data - at an average specimen temperature close to $43^{\circ} \mathrm{C}$ - suggest the high sensitivity to the loss of degree of saturation during thermal conductivity measurement with flow orthogonal to bedding planes (refer to the important differences between $\lambda_{/ /}$and $\lambda_{\perp}$ when following Pr-1, which is not only a consequence of anisotropic features but also on small changes in degree of saturation). Anisotropic features were detected when following Pr2 , with higher saturated thermal conductivity when flow was parallel to bedding planes (average $\lambda_{/ /}=2.12 \mathrm{Wm}^{-1} \mathrm{~K}^{-1}$ versus average $\lambda_{\perp}=1.83 \mathrm{Wm}^{-1} \mathrm{~K}^{-1}$, with $\eta_{T}=\lambda_{/ /} / \lambda_{\perp}=1.16$ that is close to the value of hydraulic anisotropy $\eta_{H}$ reported in Table 2).

This anisotropy has been modelled using the saturated rock matrix $\lambda_{\text {sat } m}=2.2 \mathrm{Wm}^{-1} \mathrm{~K}^{-1}$ with embedded fissures filled with free water $\lambda_{w}=0.6 \mathrm{Wm}^{-1} \mathrm{~K}^{-1}$ that are oriented parallel or orthogonal to heat flow. The equivalent saturated thermal conductivities are computed considering multi-layer systems in series (flow orthogonal to fissures), and multi-layer materials parallel to flow, as follows

$$
\begin{gathered}
\frac{1}{\lambda_{\perp}}=\frac{\chi}{\lambda_{w}}+\frac{(1-\chi)}{\lambda_{\text {sat } m}} ; \lambda / /=\chi \lambda_{w}+(1-\chi) \lambda_{\text {sat } m} \\
\eta_{T}=\frac{\lambda_{/ /}}{\lambda_{\perp}}=\left[1+\chi\left(1-\eta_{\lambda}{ }^{-1}\right)\right]\left[1+\chi\left(\eta_{\lambda}-1\right)\right] ; \eta_{\lambda}=\frac{\lambda_{\text {sat } m}}{\lambda_{w}}=3.67
\end{gathered}
$$


where $\chi$ is a characteristic physical feature of the clay that weights the role of fissures on the thermal response and can be expressed as $\chi=b / a(b$ represents the fissure aperture and $a$ is the separation between fissures). A parameter $\chi=0.0733$ can be obtained for saturated conditions by fitting experimental results. For a fissure aperture associated with the dominant pore mode of $b=7 \times 10^{-7} \mathrm{~m}$ (refer to section 2 ), the separation between fissures is $a=9.5 \times 10^{-6} \mathrm{~m}$ ([18] reports a value $a=3 \times 10^{-5} \mathrm{~m}$ for Boom Clay dealing with gas migration through pressure-dependent fissures). Figure 8 shows the fitted results at full saturation for the two orientations $\left(\lambda_{/ /}=2.08 \mathrm{Wm}^{-1} \mathrm{~K}^{-1}, \lambda_{\perp}=1.84 \mathrm{Wm}^{-1} \mathrm{~K}^{-1}\right.$ and $\eta_{T}=\lambda_{/ /}$ $\left./ \lambda_{\perp}=1.13\right)$. These values have been extrapolated to partially saturated conditions using Eq. (3) (i.e., the same effect on both orientations).

\section{Heating cell and simulation aided techniques}

\subsection{Experimental setup, sample preparation and test results}

A complementary approach was followed to further study the thermal conductivity using a heating cell, in which the sample was hydraulically pre-conditioned before the thermal tests to ensure full saturation. Figure 9 shows a scheme and a picture of the constant volume (isochoric) and axi-symmetric heating cell [13-15, 29], which is used to perform heating pulse tests with controlled power supply and controlled hydraulic state of the material (ensuring full saturation conditions). Soil sample size is $75 \mathrm{~mm}$ in diameter and $100 \mathrm{~mm}$ high. A controlled-power heater is installed along the axis of the sample in the lower part of the cell ( $\mathrm{H}$ in the figure on the left). Different transducers monitor the sample response, as shown in the Figure 9 on the left: four thermocouples ( $\mathrm{T}_{1}$ close to the heater; $\mathrm{T}_{2}$ and $\mathrm{T}_{3}$ near the sample lateral boundaries; and $\mathrm{T}_{4}$ measuring room temperature at around $20^{\circ} \mathrm{C}$ ), and two miniature pore water pressure transducers ( $\mathrm{Pw}_{1}$ and $\left.\mathrm{Pw}_{2}\right)$. The cell is equipped with top and bottom valves ( $\mathrm{u}_{\mathrm{u}}$ and $\mathrm{ub}$ ) to allow pre-conditioning of the sample before running the thermal tests (vertical flow to ensure saturation), as well as to apply controlled hydraulic boundary conditions during the heating pulse tests (elevated water back-pressure).

A specimen of Ypresian clay was trimmed to the dimensions of the cell and tested with bedding planes orthogonal to the axis of symmetry of the heating cell (hydraulic flow orthogonal to bedding planes). Two boreholes of $1.5 \mathrm{~mm}$ in diameter and $10 \mathrm{~mm}$ in depth 
were drilled in the specimen to install the thermocouples (two additional boreholes $6 \mathrm{~mm}$ in diameter and $5 \mathrm{~mm}$ in depth were required to place the water pressure transducers). Thermal grease was applied in the heater-soil contact to ensure a good thermal transfer. For the back-analysis and the numerical simulation of the thermal results it is very important to know the exact position of the thermocouples and to ensure a correct contact with the sample.

The initial conditions of the core were $w=27.1 \%, e=0.78$ and $S_{r}=0.96$. A preconditioning protocol was therefore required to increase this degree of saturation. A backpressure of 1.0 MPa at the bottom cap (ub) was initially applied in steps, leaving the top cap $\left(\mathrm{u}_{\mathrm{u}}\right)$ under atmospheric conditions. At the end of this stage, the water permeability was measured giving a value $k_{w \perp}=6.5 \times 10^{-12} \mathrm{~m} / \mathrm{s}$, which is in agreement with the information reported in Table 2. A final hydration stage along the last 13 days and before the thermal tests was performed by increasing the back-pressure at the bottom cap (ub) to 1.2 $\mathrm{MPa}$ and by closing the top valve $\mathrm{u}_{\mathrm{u}}$ (this condition was kept along the heating stages). This hydraulic pre-conditioning procedure lasted 27 days in total.

The heater with controlled power supply remained switched on for 24 hours during the heating (pulse) stage and afterwards it was switched off to perform the cooling stage. The initial and external temperatures were regulated at $T_{4} \approx 20^{\circ} \mathrm{C}$ in the temperature controlled room. Electric power supplied to the heater was calculated from the voltage and current applied. Tests ended when the soil temperature reached the initial value (around $20^{\circ} \mathrm{C}$ ). A heating pulse stage with a power supply of $9.58 \mathrm{~W}$ (maximum temperature at the heater of $56^{\circ} \mathrm{C}$ ) was carried out. Maximum temperature was limited to the highest value of the thermal conductivity tests (section 3.2) to keep the effects of temperature dependence on thermal conductivity as low as possible. Figure 10 displays the time evolutions of temperatures for different locations and along the heating and cooling stages. Maximum temperature on $\mathrm{T}_{2}$ was around $34.5^{\circ} \mathrm{C}$, while $\mathrm{T}_{3}$ reached $30.0^{\circ} \mathrm{C}$.

\subsection{Numerical simulations, boundary conditions and back-analysis of thermal parameters}

Numerical simulations of heating pulse tests using the finite element program CODE_BRIGHT [30] were performed for the interpretation and back-analysis of the test 
results. It was assumed that the driving process for temperature change during the tests was conduction only, governed by Fourier's law with constant thermal conductivity given the limited temperature range used and the constant volume condition. It means that the temperatures and heat flux were not influenced by water pressure and flow. Indeed, the low permeability of the material prevented the existence of high velocities for the liquid phase. This assumption was also justified by the condition of constant overall volume prevailing in the heating cell that made the change in porosity and the velocities of the solid phase very small. The flux of heat being transported through convection by the solid and liquid phases was, therefore, extremely low (low Péclet number $P e<0.001$ indicating conduction-dominated heat flux).

The geometry and the thermal boundary conditions used for the numerical analyses of the heating pulse stages are shown in Figure 11. Taking advantage of the radial symmetry of the cell, the model used was 2D axi-symmetric. To capture in detail temperature evolutions, all the parts of the cell with their corresponding materials were taken into account: upper/bottom lids, ring and heater (all in stainless steel); coarse porous metallic discs (sintered bronze filter); and bottom insulation for the heater (epoxy resin). Power injected by the heater was represented by an internal volumetric source term applied at all the nodes of the heater $\left(7.04 \times 10^{6} \mathrm{Wm}^{-3}\right.$ for a heater power of $\left.9.58 \mathrm{~W}\right)$. Along the revolution axis, a null flux of heat was prescribed.

Heat exchanged by the highly conductive stainless steel cell with the average controlled room air temperature at $T_{0}=20^{\circ} \mathrm{C}$ was accounted for as a convection-type boundary condition of the problem. The heat flux $q$ from the solid to the fluid can be expressed by the following equation

$$
q=h\left(T_{s}-T_{0}\right)
$$

where $T_{s}$ is the temperature of the metallic surface and $h$ is the constant convective (film) heat-transfer coefficient that is usually assumed dependent on fluid properties and temperature differences [31].

Table 7 presents the thermal parameters (constant thermal conductivity and solid phase specific heat) for the different components. The solid phase specific heat of Ypresian 
clays was determined in this study by the method of mixtures (see for instance, Ref. [32]), in which a known mass of hot dry clay (at defined temperature) was mixed with a known mass of colder water in a calorimeter until equilibrium of temperature was reached at around $24^{\circ} \mathrm{C}$. Measured values of the solid specific heat were $(970 \pm 60) \mathrm{Jkg}^{-1} \mathrm{~K}^{-1}$. Data presented by Ref. [10] using a calorimeter on the same clay at the present depth of interest indicated a dry (solid) specific heat of $(974 \pm 30) \mathrm{Jkg}^{-1} \mathrm{~K}^{-1}$ at $35^{\circ} \mathrm{C}$. I.N.I.S.Ma [10] also reported a low temperature dependence on dry specific heat within the testing temperature range (lower than $4 \mathrm{Jkg}^{-1} \mathrm{~K}^{-1} / \mathrm{K}$ for temperatures between $35^{\circ} \mathrm{C}$ and $55^{\circ} \mathrm{C}$ ). The soil specific heat under fully saturated conditions based on measured solid specific heat can be estimated in $(1695 \pm 45) \mathrm{Jkg}^{-1} \mathrm{~K}^{-1}$.

Calculations were performed for different combinations of the saturated thermal conductivity $\lambda$ and the convective coefficient $h$. For each of them, a measure of the least squares differences $\varepsilon$ between temperature simulation results and temperature experimental measurements was computed by the following equation for different elapsed times under steady-state conditions

$$
\varepsilon=\frac{\sqrt{\sum_{i=1}^{n_{s}} \sum_{j=1}^{n_{t}}\left[T_{i}^{\text {sim }}\left(t_{j}\right)-T_{i}^{\text {meas }}\left(t_{j}\right)\right]^{2}}}{n_{s} n_{t}}
$$

where $T_{i}^{\text {sim }}\left(t_{j}\right)$ and $T_{i}^{\text {meas }}\left(t_{j}\right)$ are, respectively, the simulated and measured values of temperature at sensor $i$ and time $t_{j}, n_{s}=3$ is the number of sensors, and $n_{t}$ the number of elapsed times used in the comparison.

The three-dimensional plot in Figure 12 displays the least squares differences $\varepsilon$ between simulation results and experimental observations. The best agreement was obtained for parameters $\lambda=1.9 \mathrm{Wm}^{-1} \mathrm{~K}^{-1}$ and $h=11 \mathrm{Wm}^{-2} \mathrm{~K}^{-1}$. The latter convective coefficient presents a consistent value, since still air usually ranges between 3 and $23 \mathrm{Wm}^{-2} \mathrm{~K}^{-1}$ [31]. The parameter $h$ is somewhat lower compared to the value reported for Boom Clay in [13-15] $\left(h=24 \mathrm{Wm}^{-2} \mathrm{~K}^{-1}\right)$, due to the fact that the setup with Boom Clay involved a more conductive still water bath to control the temperature at the boundaries of the heating cell. 
The back-analysed saturated thermal conductivity has been plotted in Figure 8 together with direct measurements. This back-analysed value measured on the transversely isotropic sample falls between the directly measured $\lambda_{/ /}$and $\lambda_{\perp}$, since it involves the combined contribution of the principal components of the thermal conductivity tensor (temperature evolution $T_{2}$ is more associated with $\lambda / /$ - line source axis orthogonal to bedding planes - which is not the case for temperature evolution $\mathrm{T}_{3}$ ).

Back-analysed thermal parameters were used to simulate test results. Figure 13 shows a comparison (experimental and numerical results) of the time evolutions of temperatures during heating and cooling phases. Simulated results during heating under steady-state conditions matched the temperature close to the heater $T_{1}$, whereas slightly underestimated the experimental records of sensors $\mathrm{T}_{2}$ and $\mathrm{T}_{3}$ (modelling results were $2.5^{\circ} \mathrm{C}$ lower). These deviations can be associated with some small temperature dependence of the thermal conductivity, as well as with spurious experimental problems: small shifting of measurement points towards the heater (particularly for sensor $\mathrm{T}_{2}$ approaching a high gradient zone of $0.96^{\circ} \mathrm{C} / \mathrm{mm}$ ) and interface problems across the contacts between sample and isochoric cell.

\section{Concluding remarks}

Small-scale laboratory tests on well preserved deep samples of a potential sedimentary argillaceous host formation (Ypresian clays retrieved at a depth around $370 \mathrm{~m}$ ) for radioactive waste disposal in Belgium have been used to explore thermal conductivity features under controlled conditions. Inconsistencies in the results on different deep sedimentary clay formations with bedding planes have required developing new testing protocols to improve some shortcomings observed and thus give confidence in the measured data. These inconsistencies arise as a consequence of the opening of fissures and gaps along bedding planes during retrieval, and the consequent loss of full saturation of the material, which mainly affects the correct determination of the thermal conductivity when heat flows orthogonal to the bedding planes. This is particularly important when exploring anisotropic features, since higher anisotropic ratios have been usually assigned 
to these formations under small-scale laboratory conditions when compared to backanalysed data of in situ heating tests.

A first test series has been performed on a new experimental setup with heaters, local measurements of temperature at different heights of the specimen and two heat flux sensors on top and bottom caps. Pre-conditioning protocols on specimens were run on a high-pressure isotropic cell with local axial and radial deformation measuring systems. These protocols consisted in isotropically loading to in situ mean stress conditions to increase the degree of saturation, followed by unloading under water-undrained conditions. An improved protocol used drainage lines filled with synthetic water of the formation before the unloading stage to avoid any air to enter. These protocols ensured higher degrees of saturation and some closure of fissures / gaps along bedding planes before the thermal tests.

A second series has been followed on an instrumented heating cell - with several thermocouples - under constant volume and controlled hydraulic boundary condition: constant and elevated water back-pressure at the bottom drainage line and top end with no flow condition that ensured full saturation. Results were presented and discussed in terms of the measurements of temperature during the application of heating and cooling stages. A finite element program was used to calibrate by back-analysis some thermal properties (saturated thermal conductivity of the soil and convective heat-transfer coefficient that controls thermal flux at the cell interface) and then to simulate selected experimental results.

Higher values than those reported by previous reports on the same sedimentary clay formation have been directly measured with the new experimental setup, as a consequence of the strict loading-unloading pre-conditioning protocol followed and in line with the elevated quartz content of the formation at the depth of interest. Clear anisotropic features have been detected, with higher thermal conductivity when heat flow was parallel to bedding planes $\left(\lambda_{/ /}=2.12 \mathrm{Wm}^{-1} \mathrm{~K}^{-1}\right)$ and with a thermal anisotropy ratio $\eta_{T}=\lambda_{/ /} / \lambda_{\perp}=1.16$. This higher thermal conductivity was also consistent with the value reported when using back-analysis methodology in the constant volume heating cell, which involved the combined contribution of the principal components of the thermal conductivity tensor (the back-analysed value measured on the transversely isotropic sample falls between the directly measured $\lambda_{/ /}$and $\lambda_{\perp}$ ). 


\section{Acknowledgements}

Financial support of ONDRAF/NIRAS (Belgium) through different collaboration agreements with International Centre for Numerical Methods in Engineering (CIMNE, Spain) is greatly acknowledged ('Thermo-hydro-mechanical research on Ypresian clays' 2010-2011 and 'Complementary tests on thermal anisotropy of the Ypresian clays' 20142015). The authors also acknowledge the support provided by the European Commission by Marie Curie IRSES project GREAT (FP7-PEOPLE-2013-IRSES-612665). Thanks are also extended to Prof. Antonio Gens and Prof. Jean Vaunat for their valuable comments regarding the numerical modelling. The authors thank the reviewers for their detailed comments on the manuscript and making several useful remarks. 


\section{References}

[1] KD Murphy, JS McCartney, KS Henry, Evaluation of thermo-mechanical and thermal behaviour of full-scale energy foundations, Acta Geotech 10 (2) (2015) 179-195.

[2] JE Low, FA Loveridge, W Powrie, D Nicholson, A comparison of laboratory and in situ methods to determine soil thermal conductivity for energy foundations and other ground heat exchanger applications, Acta Geotech 10 (2) (2015) 209-218.

[3] A Bidarmaghz, GA Narsilio, IW Johnston, S Colls, The importance of surface air temperature fluctuations on long-term performance of vertical ground heat exchangers, Geomech Energy Environ 6 (2016) 35-44.

[4] Y Dong, JS McCartney, N Lu, Critical review of thermal conductivity models for unsaturated soils, C G Geotech Geol Eng 33 (2015) 207-221.

[5] ONDRAF/NIRAS Research. Development and Demonstration (RD\&D) Plan for the geological disposal of high-level and/or long-lived radioactive waste including irradiated fuel if considered as waste. State-of-the-art report as of December 2012. Report NIROND-TR 2013-12 E, Belgian Agency for Radioactive Waste and Enriched Fissile Materials ONDRAF/NIRAS, Brussels, Belgium, 2013.

[6] GJ Chen, X Sillen, J Verstricht, X Li, ATLAS III in situ heating test in Boom Clay: field data, observation and interpretation, Comput Geotech 38 (5) (2011) 683-696.

[7] B Garitte, A Gens, J Vaunat, G Armand, Thermal conductivity of argillaceous rocks: Determination methodology using in situ heating tests, Rock Mech Rock Eng 47 (1) (2014) 111-129.

[8] L Dao, P Delage, AM Tang, Y-J Cui, J-M Pereira, X Li, X Sillen, Anisotropic thermal conductivity of natural Boom Clay, Appl Clay Sci 101 (2014) 282-287.

[9] L Dao, Y-J Cui, AM Tang, J-M Pereira, X Li, X Sillen, Impact of excavation damage on the thermo-hydro-mechanical properties of natural Boom Clay, Eng Geol 195 (2015) 196-205.

[10] I.N.I.S. Ma. Technical report no 74252. Mons, Belgium. 1998.

[11] Leuven KU. Laboratory for Applied Geology \& Mineralogy, Technical report. Leuven, Belgium. 2011.

[12] Qmineral. Technical report no 1406AE. Heverlee, Belgium. 2014.

[13] A Lima, E Romero, A Gens, J Vaunat, Coupled thermo-hydraulic pulse tests on two reference Belgian clay formations, In: Coupled Phenomena in Environmental Geotechnics, CRC Press, London, 2013, pp. 413-417. 
[14] E Romero, A Lima, A Gens, J Vaunat, X Li, Determination of the thermal parameters of a clay from heating cell tests, In: Proc. 18th Int. Conf. on Soil Mechanics and Geotechnical Engineering, Presses des Ponts, Paris, 2013, pp. 3403-3406.

[15] A Lima, Thermo-hydro-mechanical behaviour of two deep Belgian clay formations: Boom and Ypresian clays, [Ph.D. thesis] Universitat Politècnica de Catalunya, Spain, 2011.

[16] Y Piña, Thermo-hydro-mechanical behaviour of Ypresian clay, MSc Thesis in Geotechnical Engineering Universitat Politècnica de Catalunya, Spain, 2011.

[17] L Gonzalez-Blanco, E Romero, X Li and X Sillen, Importance of sample volume changes and material degradation on gas transport properties in Boom Clay. In: Proc. 7th Int. Cong. on Environmental Geothecnics. Melbourne, Australia. 2014:850-857.

[18] L Gonzalez-Blanco, E Romero, C Jommi, X Li, X Sillen, Gas migration in a Cenozoic clay: Experimental results and numerical modelling, Geomech Energy Environ 6 (2016) 81-100.

[19] XP Nguyen, Y-J Cui, AM Tang, X Li, L Wouters, Physical and microstructural impacts on the hydro-mechanical behaviour of Ypresian clays, Appl Clay Sci 102 (2014) 172-185.

[20] XP Nguyen, Étude du comportement chimico-hydro-mécanique des argiles raides dans le contexte du stockage géologique de déchets radioactifs, [Ph.D. thesis] Ecole des Ponts ParisTech, France, 2013.

[21] O Johansen. Thermal conductivity of soils [Ph.D. thesis]. Trondheim, Norway (CRREL Draft Translation 637, 1977) ADA 044002. 1975.

[22] KI Horai, Thermal conductivity of rock-forming minerals, J Geophys Res 76 (5) (1971) 1278-1308.

[23] OT Farouki, Thermal Properties of Soils, Clausthal-Zellerfeld, Trans Tech Publications, Germany, 1986.

[24] J Cheh, Y Gao, C Wang, H Zhao, H Fang, Ice or water: thermal properties of monolayer water adsorbed on a substrate, J Stat Mech Theory Exp (2013) P06009.

[25] E Romero, Characterisation and thermo-hydro-mechanical behaviour of unsaturated Boom Clay: An experimental study, [Ph.D. thesis] Universitat Politècnica de Catalunya, Spain, 1999.

[26] D Barry-Macaulay, A Bouazza, RM Singh, B Wang, PG Ranjith, Thermal conductivity of soils and rocks from the Melbourne (Australia) region, Eng Geol 164 (2013) 131-138. 
[27] E Romero, N Sau, A Lima, H Van Baelen, X Sillen, X Li, Anisotropic features on the thermal conductivity of a deep argillaceous formation, in: D Manzanal, AO Sfriso (Eds.), Proc. 15th Pan-American Conference on Soil Mechanics and Geotechnical Engineering, 15 - 18 November 2015, Buenos Aires, Argentina. From Fundamentals to Applications in Geotechnics, IOS Press, 2015.

[28] AR Lappin, Thermal conductivity of silicic tuffs: Predictive formalism and comparison with preliminary experimental results. Technical report no SAND800769, Sandia National Laboratories, Alburquerque, USA, 1980.

[29] JJ Muñoz, EE Alonso, A Lloret, Thermo-hydraulic characterization of soft rock by means of heating pulse tests, Géotechnique 59 (4) (2009) 293-306.

[30] S Olivella, A Gens, J Carrera, EE Alonso, Numerical formulation for a simulator (CODE_BRIGHT) for the coupled analysis of saline media, Int J Eng Comput 13 (7) (1996) 87-112.

[31] CJ Geankoplis, In: Transport Processes-Momentum, Heat, and Mass, Allyn and Bacon Series in Engineering, Allyn and Bacon, Inc., Massachusetts, USA, 1983.

[32] KA Alnefaie, NH Abu-Hamdeh, Specific heat and volumetric heat capacity of some Saudian soils as affected by moisture and density. In: Proc. Int. Conf. on Mechanics, Fluids, Heat, Elasticity and Electromagnetic Fields, Venice. 2013:139-143. 


\section{TABLES:}

Table 1. Thermal conductivity values of Boom Clay for two different orientations (orthogonal and parallel to bedding planes) obtained from different recent sources. Results of the present study with direct determination on saturated material.

\begin{tabular}{|c|c|c|c|c|}
\hline Source & $\begin{array}{c}\text { Methodology used (degree of } \\
\text { saturation) }\end{array}$ & $\lambda_{\perp}\left(\mathbf{W m}^{-1} \mathbf{K}^{-1}\right)$ & $\lambda_{/ /}\left(\mathbf{W} \mathbf{m}^{-1} \mathbf{K}^{-1}\right)$ & $\eta_{T}$ \\
\hline $\begin{array}{l}\text { Chen et al. } \\
\text { (2011) [6] }\end{array}$ & $\begin{array}{c}\text { Back-analysis from ATLAS III } \\
\text { in situ test }\left(S_{r}=1\right) . \\
\text { In situ stress conditions }\end{array}$ & 1.31 & 1.65 & 1.30 \\
\hline $\begin{array}{l}\text { Lima et al. } \\
(2013)[13] \\
\text { Romero et al. } \\
(2013)[14]\end{array}$ & $\begin{array}{c}\text { Back-analysis from laboratory } \\
\text { pulse heating tests }\left(S_{r}=1\right) . \\
\text { Constant volume conditions }\end{array}$ & - & 1.60 & - \\
\hline $\begin{array}{l}\text { Garitte et al. } \\
\text { (2014) [7] }\end{array}$ & $\begin{array}{c}\text { Back-analysis from ATLAS III } \\
\text { in situ test } \quad\left(S_{r}=1\right) . \\
\text { In situ stress conditions }\end{array}$ & 1.06 & 1.55 & 1.46 \\
\hline $\begin{array}{l}\text { Dao et al. } \\
(2015)[9]\end{array}$ & $\begin{array}{l}\text { Laboratory (thermal needle } \\
\text { probe on samples from EDZ*) } \\
\left(S_{r}=0.86 \text { at } r=9.2 \mathrm{~m}\right) \\
\text { Low stress conditions }\end{array}$ & $\begin{array}{c}0.94 \\
(r=9.2 \mathrm{~m})\end{array}$ & $\begin{array}{c}1.61 \\
(r=9.2 \mathrm{~m})\end{array}$ & $\begin{array}{c}1.71 \\
(r=9.2 \mathrm{~m})\end{array}$ \\
\hline Present study & $\begin{array}{l}\text { Thermal conductivity setup } \\
\left(S_{r}=1\right) \text {. Low stress conditions }\end{array}$ & 1.17 & 1.59 & 1.36 \\
\hline
\end{tabular}

*Excavation Damaged Zone at different distances $r$ from the gallery axis. 
Table 2. Properties of Ypresian clays (Kallo 1 site, cores \#83 and \#84). Properties of Boom Clay that will be used in section 3.3 devoted to the preliminary thermal conductivity tests.

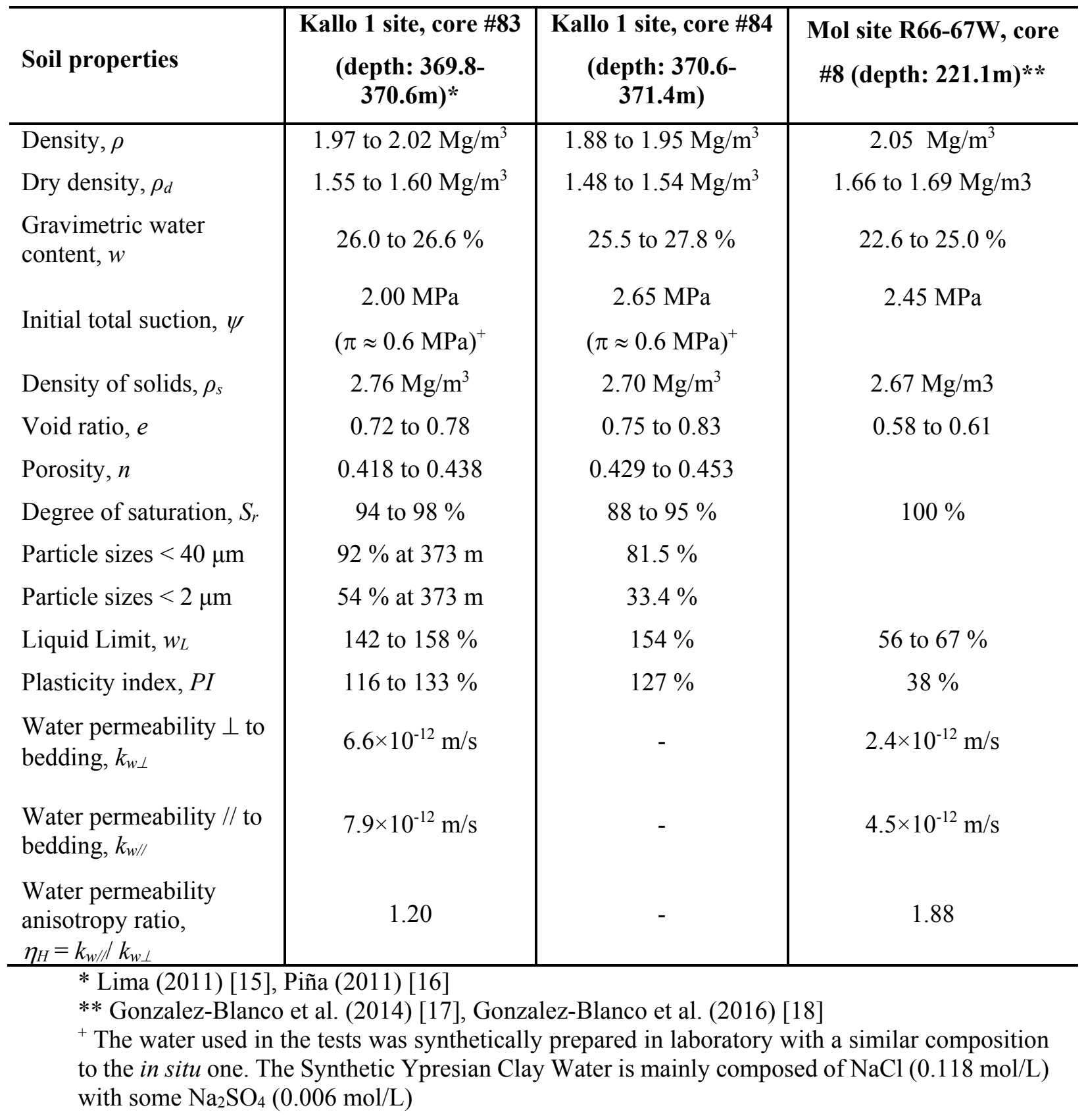


Table 3. Summary of Ypresian clay specimens, protocols followed and as-retrieved conditions.

\begin{tabular}{|c|c|c|c|c|c|}
\hline Specimen & $\begin{array}{c}\text { Pre-conditioning } \\
\text { protocol }\end{array}$ & $\begin{array}{c}\text { Density, } \rho \\
\left(\mathrm{Mg} / \mathbf{m}^{3}\right)\end{array}$ & $\begin{array}{c}\text { Water } \\
\text { content, } w \\
(\%)\end{array}$ & $\begin{array}{l}\text { Void } \\
\text { ratio, } e\end{array}$ & $\begin{array}{c}\text { Degree of } \\
\text { saturation, } S_{r}\end{array}$ \\
\hline Y1-N & \multirow{2}{*}{$\mathrm{W} / \mathrm{P}$} & 1.87 & 26.9 & 0.828 & 0.877 \\
\hline Y11-N & & 1.93 & 25.8 & 0.758 & 0.919 \\
\hline Y4-N & \multirow{2}{*}{ Pr-1 } & 1.90 & 25.5 & 0.782 & 0.881 \\
\hline Y5-P & & 1.90 & 25.7 & 0.790 & 0.878 \\
\hline Y2-P & \multirow{5}{*}{ Pr-2 } & 1.93 & 25.1 & 0.752 & 0.901 \\
\hline Y3-N & & 1.95 & 27.7 & 0.769 & 0.972 \\
\hline Y8-P & & 1.94 & 25.9 & 0.752 & 0.930 \\
\hline Y9-N & & 1.94 & 25.8 & 0.753 & 0.925 \\
\hline Y10-N & & 1.94 & 26.3 & 0.756 & 0.939 \\
\hline
\end{tabular}


Table 4. Properties of statically compacted Ypresian clay samples. Thermal conductivity results.

\begin{tabular}{cccccc}
\hline Specimen & $\begin{array}{c}\text { Void ratio, } \\
\end{array}$ & $\begin{array}{c}\text { Water content, } \\
\boldsymbol{e}(\boldsymbol{\%})\end{array}$ & $\begin{array}{c}\text { Degree of } \\
\text { saturation, } \boldsymbol{S}_{\boldsymbol{r}}\end{array}$ & $\begin{array}{c}\lambda \\
\left(\mathbf{W m ^ { - 1 }} \mathbf{K}^{-\mathbf{1}}\right)\end{array}$ & $\lambda / \boldsymbol{\lambda}_{\text {sat }}$ \\
\hline YC-70 & 0.80 & 20.1 & 0.68 & 1.41 & 0.61 \\
YC-80 & 0.80 & 22.4 & 0.76 & 1.61 & 0.70 \\
YC-90 & 0.80 & 26.7 & 0.90 & 2.01 & 0.87 \\
YC-100 & 0.80 & 29.6 & 1 & 2.30 & 1 \\
\hline
\end{tabular}

Table 5. Test results from loading-unloading pre-conditioning paths.

\begin{tabular}{ccccccccc}
\hline Specimen & $\begin{array}{c}\text { Pre- } \\
\text { conditioning } \\
\text { protocol }\end{array}$ & $\boldsymbol{S}_{\boldsymbol{r} \boldsymbol{0}^{+}}$ & $\boldsymbol{\Delta} \boldsymbol{c}$ & $\begin{array}{c}\boldsymbol{\Delta} \boldsymbol{\varepsilon}_{\boldsymbol{v}} \\
\boldsymbol{( \% )}\end{array}$ & $\boldsymbol{S}_{\boldsymbol{r}}$ & $\boldsymbol{\Delta} \boldsymbol{e}$ & $\begin{array}{c}\boldsymbol{\Delta} \boldsymbol{\varepsilon}_{\boldsymbol{v}} \\
(\boldsymbol{\%})\end{array}$ & $\boldsymbol{S}_{\boldsymbol{r}}$ \\
\hline Y1-N & $\mathrm{W} / \mathrm{P}$ & 0.877 & & & & & & \\
Y11-N & & 0.919 & & & & & & \\
\hline Y4-N & $\mathrm{Pr}-1$ & 0.881 & -0.061 & 3.41 & 0.955 & 0.010 & -0.55 & 0.943 \\
Y5-P & & 0.878 & -0.092 & 5.16 & 0.995 & 0.014 & -0.79 & 0.975 \\
\hline Y2-P & & 0.901 & -0.077 & 4.37 & 1 & 0.014 & -0.78 & 0.980 \\
Y3-N & & 0.972 & -0.037 & 2.10 & 1 & 0.009 & -0.49 & 0.988 \\
Y8-P & Pr-2 & 0.930 & -0.043 & 2.43 & 0.986 & 0.010 & -0.56 & 0.972 \\
Y9-N & & 0.925 & -0.090 & 5.16 & 1 & 0.007 & -0.42 & 0.990 \\
Y10-N & & 0.939 & -0.052 & 2.96 & 1 & 0.012 & -0.67 & 0.984 \\
\hline
\end{tabular}

*Void ratio change and volumetric deformation on loading. Degree of saturation after loading. **Void ratio change and volumetric deformation on unloading. Degree of saturation after unloading.

${ }^{+}$Initial degree of saturation (as-retrieved condition). 
Table 6. Results from thermal conductivity tests.

\begin{tabular}{|c|c|c|c|c|c|c|}
\hline Specimen & $\begin{array}{c}\text { Pre- } \\
\text { conditioning } \\
\text { protocol }\end{array}$ & $w_{i}(\%)^{*}$ & $\begin{array}{c}w_{f}(\%)^{* * *} \\
\text { (top, bottom) }\end{array}$ & $S_{r}^{+}$ & $\begin{array}{c}\lambda_{\perp} \\
\left(\mathbf{W m}^{-1} \mathbf{K}^{-1}\right)\end{array}$ & $\begin{array}{c}\lambda / / \\
\left(\mathbf{W m}^{-1} \mathbf{K}^{-1}\right)\end{array}$ \\
\hline Y1-N & $\mathrm{W} / \mathrm{P}$ & 26.9 & - & 87.7 & 1.39 & - \\
\hline Y11-N & $\mathrm{W} / \mathrm{P}$ & 25.8 & - & 91.9 & 1.39 & - \\
\hline Y4-N & Pr-1 & 25.5 & $\begin{array}{c}24.7 \\
(24.0,25.4)\end{array}$ & 94.3 & $1.42 \pm 0.02$ & - \\
\hline Y5-P & Pr-1 & 25.7 & $\begin{array}{c}24.2 \\
(23.8,24.3)\end{array}$ & 97.5 & - & $1.95 \pm 0.01$ \\
\hline Y2-P & Pr-2 & 25.1 & $\begin{array}{c}23.5 \\
(22.9,24.4)\end{array}$ & 98.0 & - & $2.06 \pm 0.03$ \\
\hline Y3-N & Pr-2 & 27.7 & - & 98.8 & 1.80 & - \\
\hline Y8-P & Pr-2 & 25.9 & $\begin{array}{c}23.3 \\
(23.0,23.6)\end{array}$ & 97.2 & - & $2.17 \pm 0.01$ \\
\hline Y9-N & Pr-2 & 25.8 & $\begin{array}{c}24.5 \\
(23.3,25.1)\end{array}$ & 99.0 & $1.84 \pm 0.03$ & - \\
\hline Y10-N & Pr-2 & 26.3 & $\begin{array}{c}24.7 \\
(24.4,24.9)\end{array}$ & 98.4 & $1.86 \pm 0.01$ & - \\
\hline
\end{tabular}

*Initial water content of the specimen (as-retrieved condition).

**Average final water content after thermal test (final water contents at top and bottom positions of the sample).

${ }^{+}$Degree of saturation just before the thermal test. 
Table 7. Thermal parameters used in the simulations and back-analysed values.

\begin{tabular}{|c|c|c|c|c|c|}
\hline \multirow{2}{*}{$\begin{array}{l}\text { Thermal } \\
\text { parameters }\end{array}$} & \multicolumn{5}{|c|}{ Materials } \\
\hline & $\begin{array}{c}\text { Stainless } \\
\text { steel }\end{array}$ & $\begin{array}{c}\text { Sintered } \\
\text { bronze filter }\end{array}$ & Epoxy resin & Ypresian clays & Cell boundary \\
\hline $\begin{array}{l}\text { Thermal } \\
\text { conductivity, } \lambda\end{array}$ & $16 \mathrm{Wm}^{-1} \mathrm{~K}^{-1}$ & $\begin{array}{c}42 \mathrm{Wm}^{-1} \mathrm{~K}^{-1} \\
\text { (saturated) }\end{array}$ & $0.6 \mathrm{Wm}^{-1} \mathrm{~K}^{-1}$ & $\begin{array}{c}1.9 \mathrm{Wm}^{-1} \mathrm{~K}^{-1} * \\
\text { (saturated) }\end{array}$ & \\
\hline $\begin{array}{l}\text { Solid phase } \\
\text { specific heat, } C_{s}\end{array}$ & $460 \mathrm{Jkg}^{-1} \mathrm{~K}^{-1}$ & $360 \mathrm{Jkg}^{-1} \mathrm{~K}^{-1}$ & $730 \mathrm{Jkg}^{-1} \mathrm{~K}^{-1}$ & $970 \mathrm{Jkg}^{-1} \mathrm{~K}^{-1} * *$ & \\
\hline $\begin{array}{l}\text { Convection } \\
\text { coefficient, } h\end{array}$ & & & & & $11 \mathrm{Wm}^{-2} \mathrm{~K}^{-1} *$ \\
\hline
\end{tabular}

* Thermal parameters from back-analyses

** Measured value using the method of mixtures: $(970 \pm 60) \mathrm{Jkg}^{-1} \mathrm{~K}^{-1}$ 


\section{FIGURES:}

Figure 1. Scheme and picture of the thermal conductivity setup with seven thermocouples. Different components of the setup: (a) Top heating cap; (b) bottom heating cap; (c) heat flux sensor; (d) miniature electrical resistance.
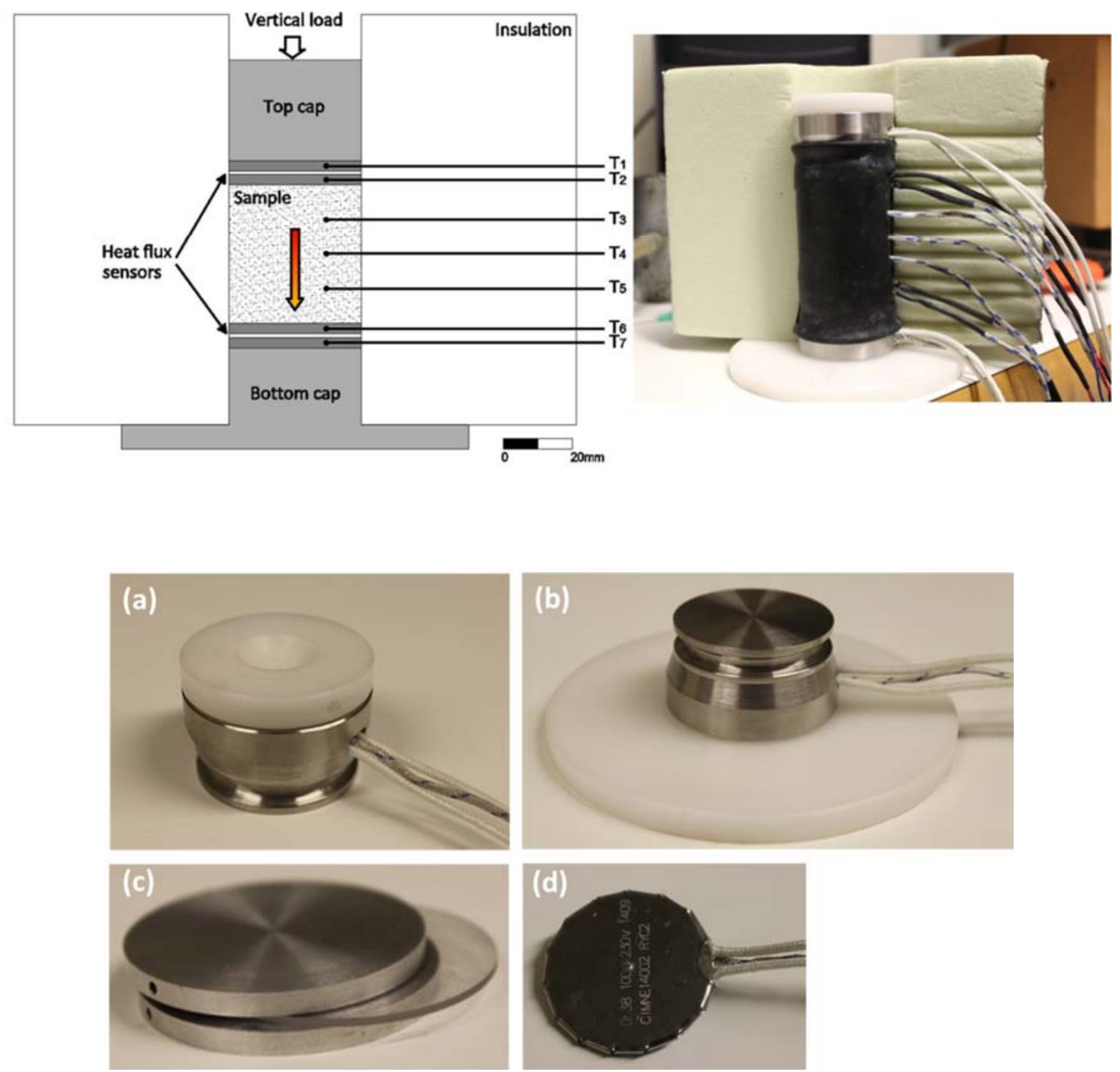
Figure 2. Preliminary tests results. Time evolution of heat losses at different vertical stresses.

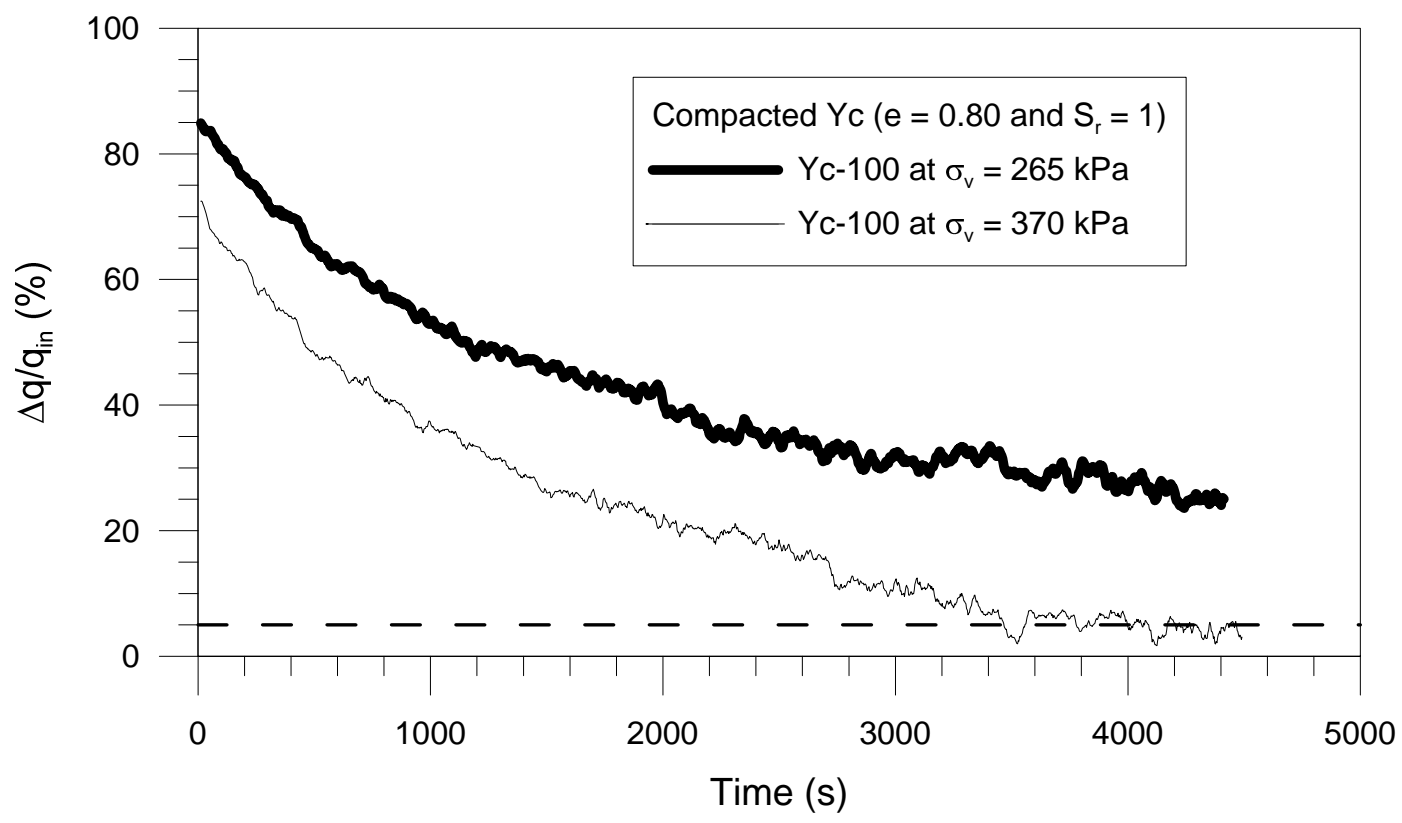


Figure 3. Normalised thermal conductivity of compacted Ypresian clays as a function of degree of saturation. Expected trend based on geometric mean method.

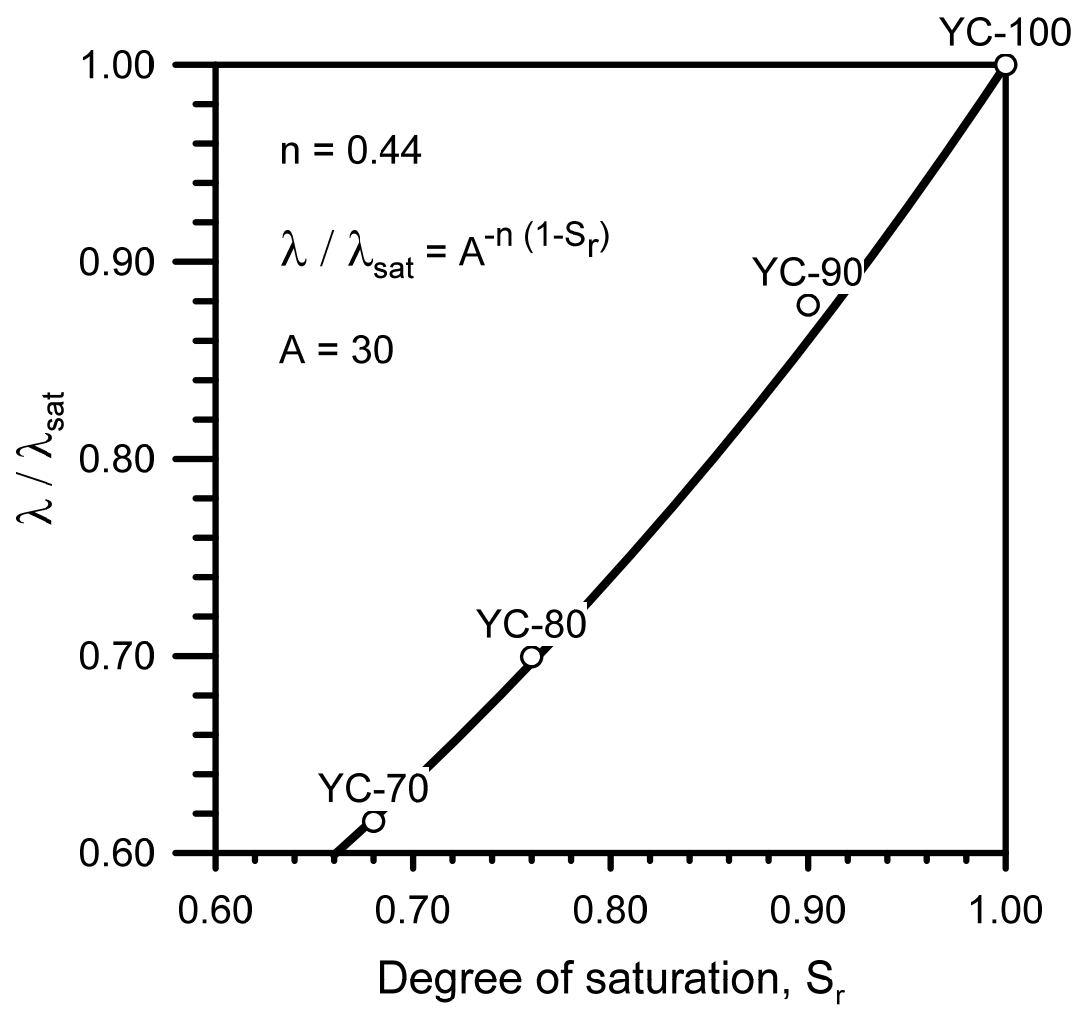


Figure 4. Isotropic loading and unloading pre-conditioning paths for tests on Y2-P (core axis parallel to bedding planes) and Y3-N (core axis orthogonal to bedding planes).

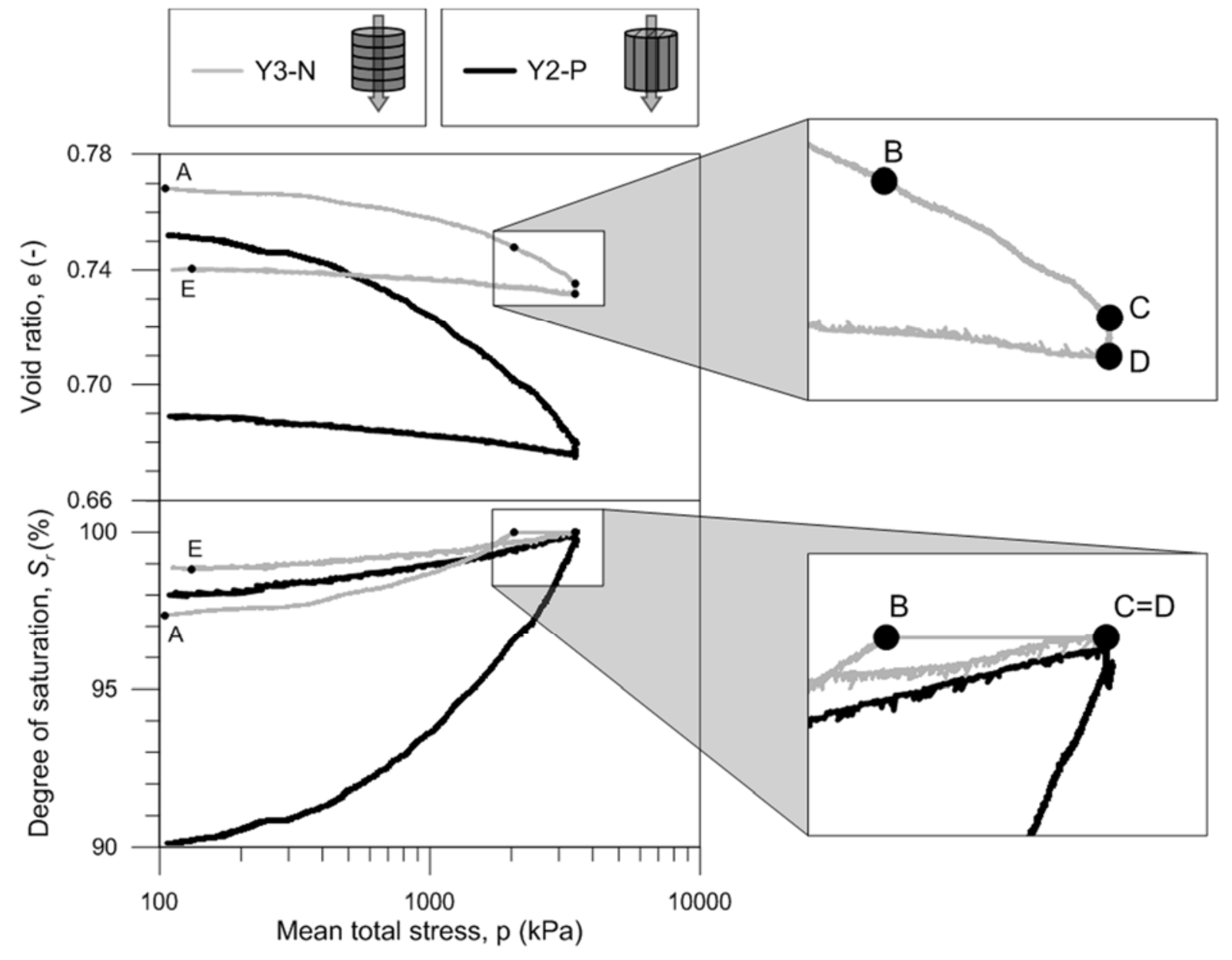


Figure 5. Time evolution of temperatures. a) Sample Y2-P. b) Sample Y3-N.

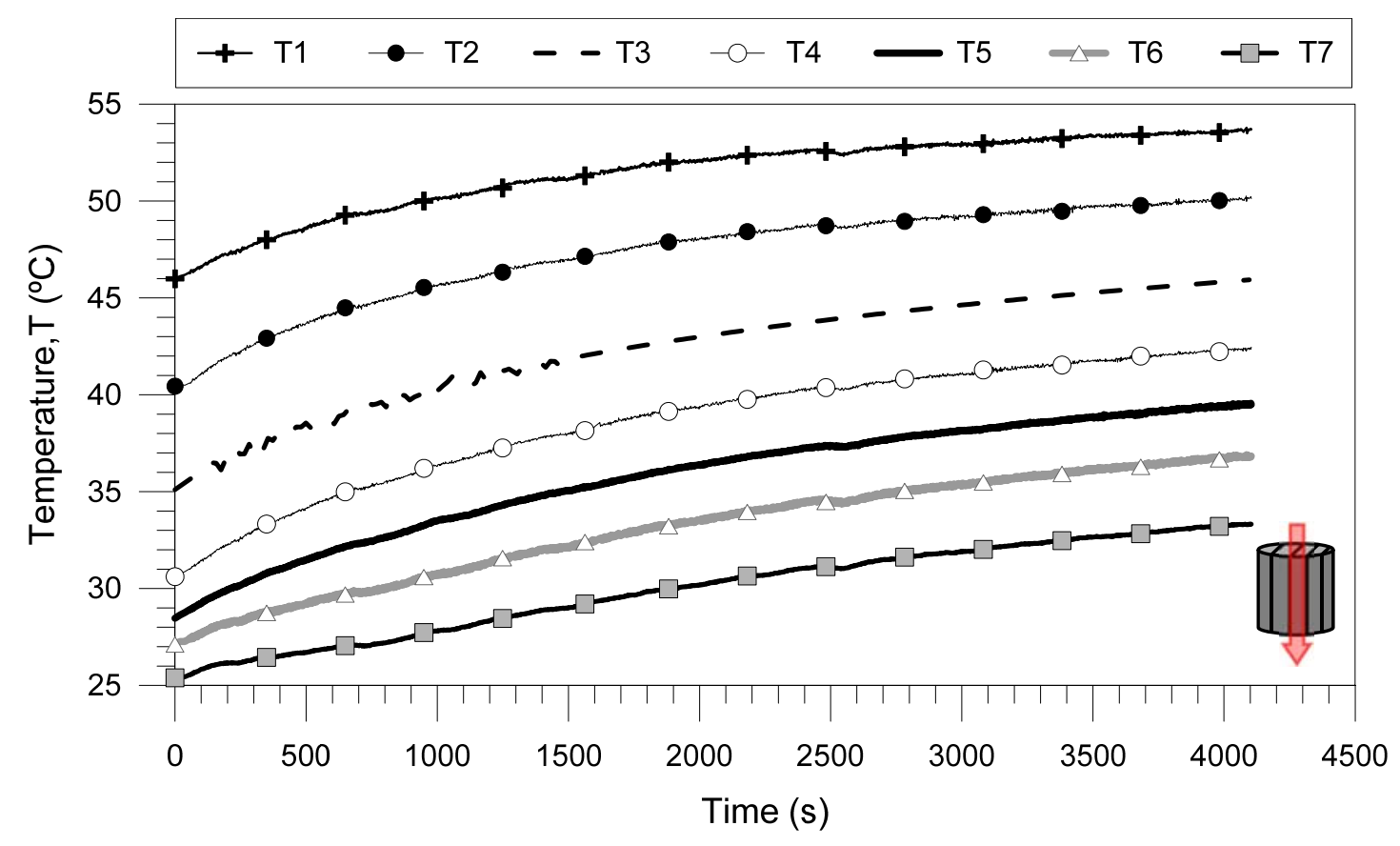

(a)

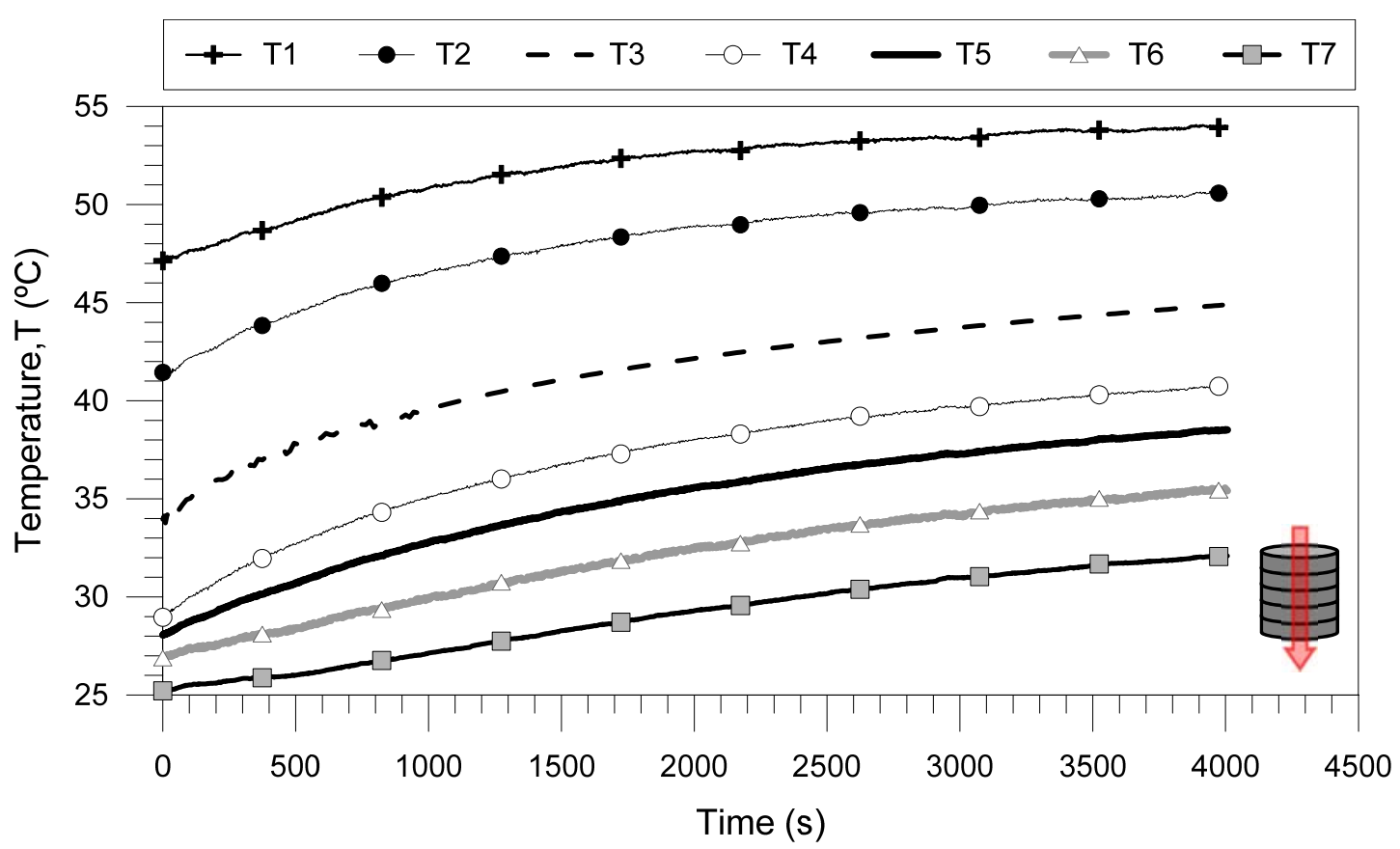

(b) 
Figure 6. Time evolution of heat fluxes (inflow, outflow and normalised difference between these fluxes). a) Sample Y2-P. b) Sample Y3-N.

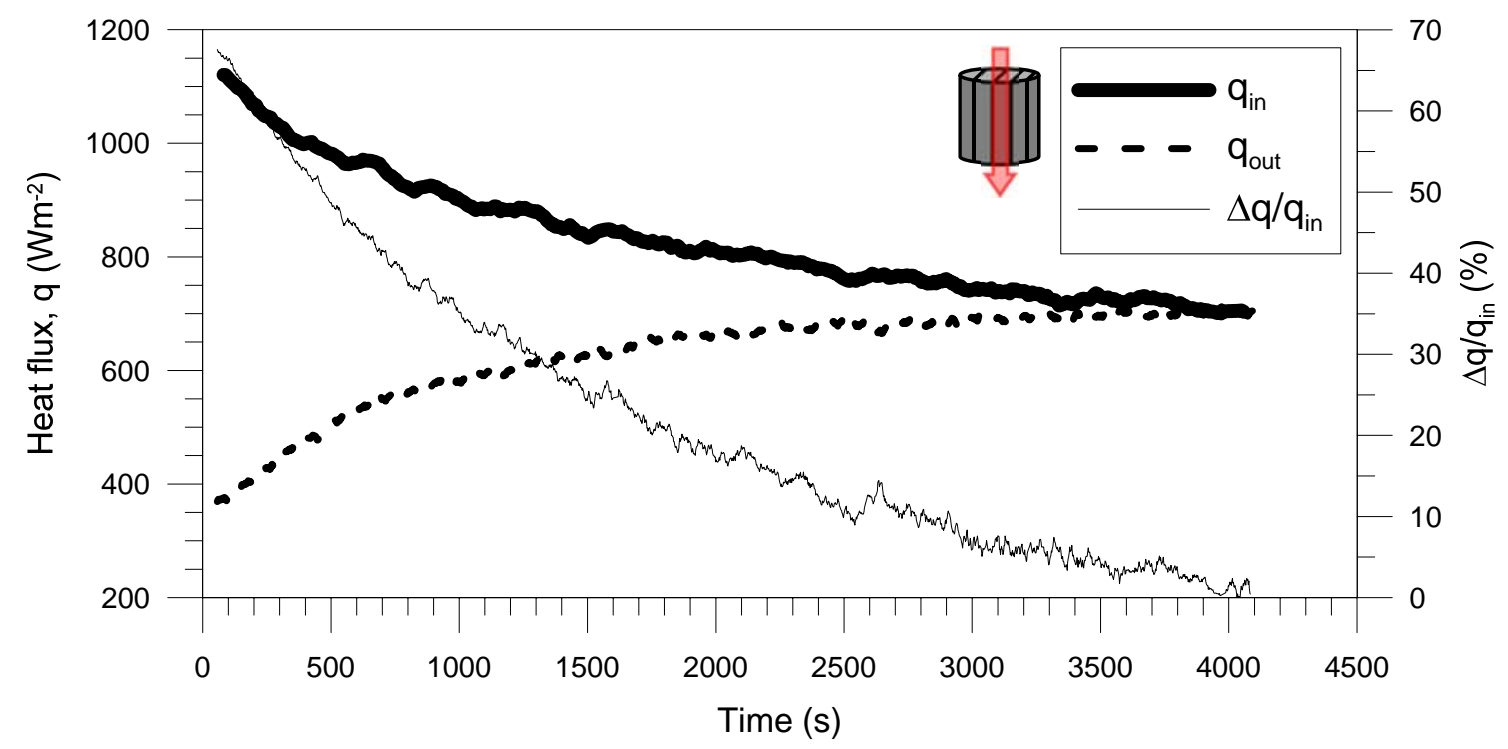

(a)

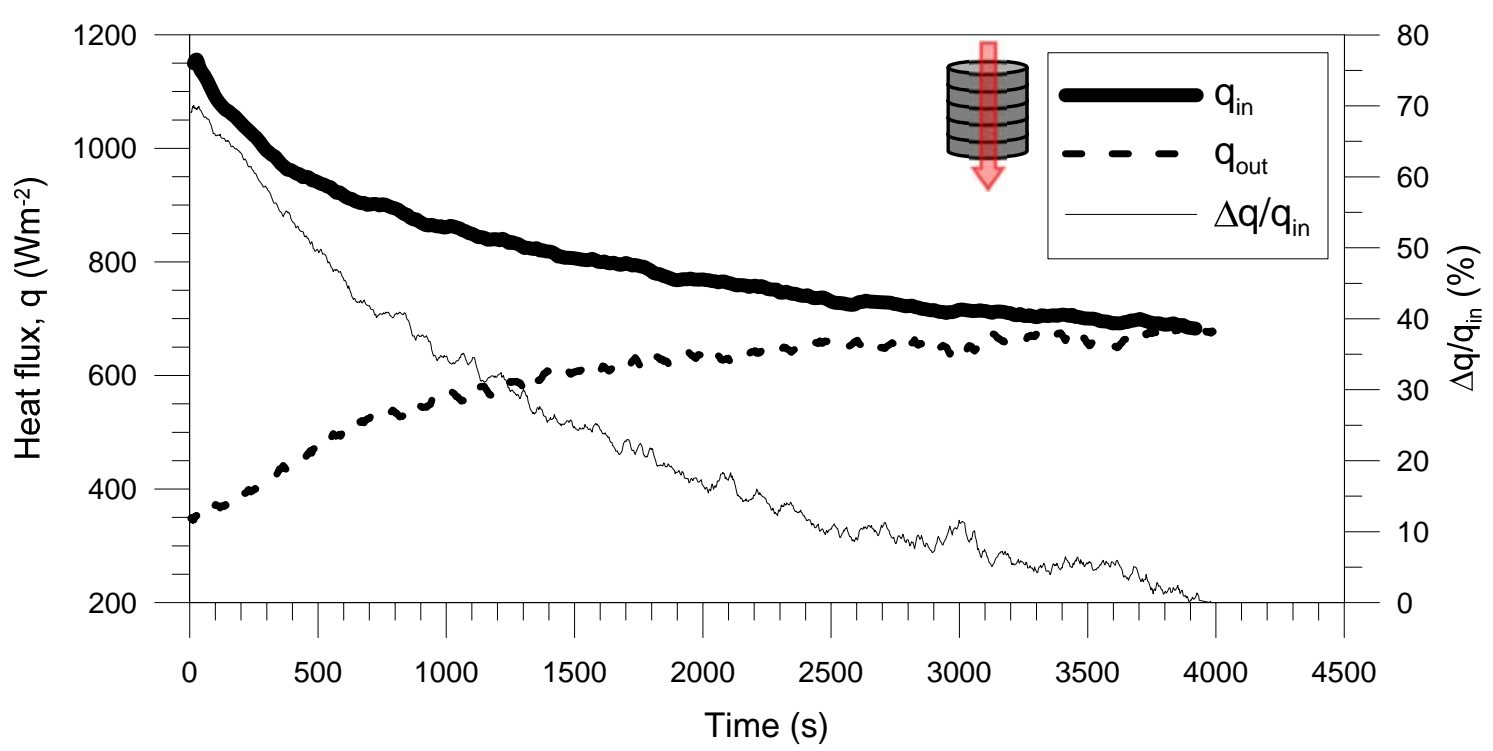

(b) 
Figure 7. Time evolution of $q_{a v e} L / \Delta T$. Thermal conductivity at steady-state conditions for all tests.

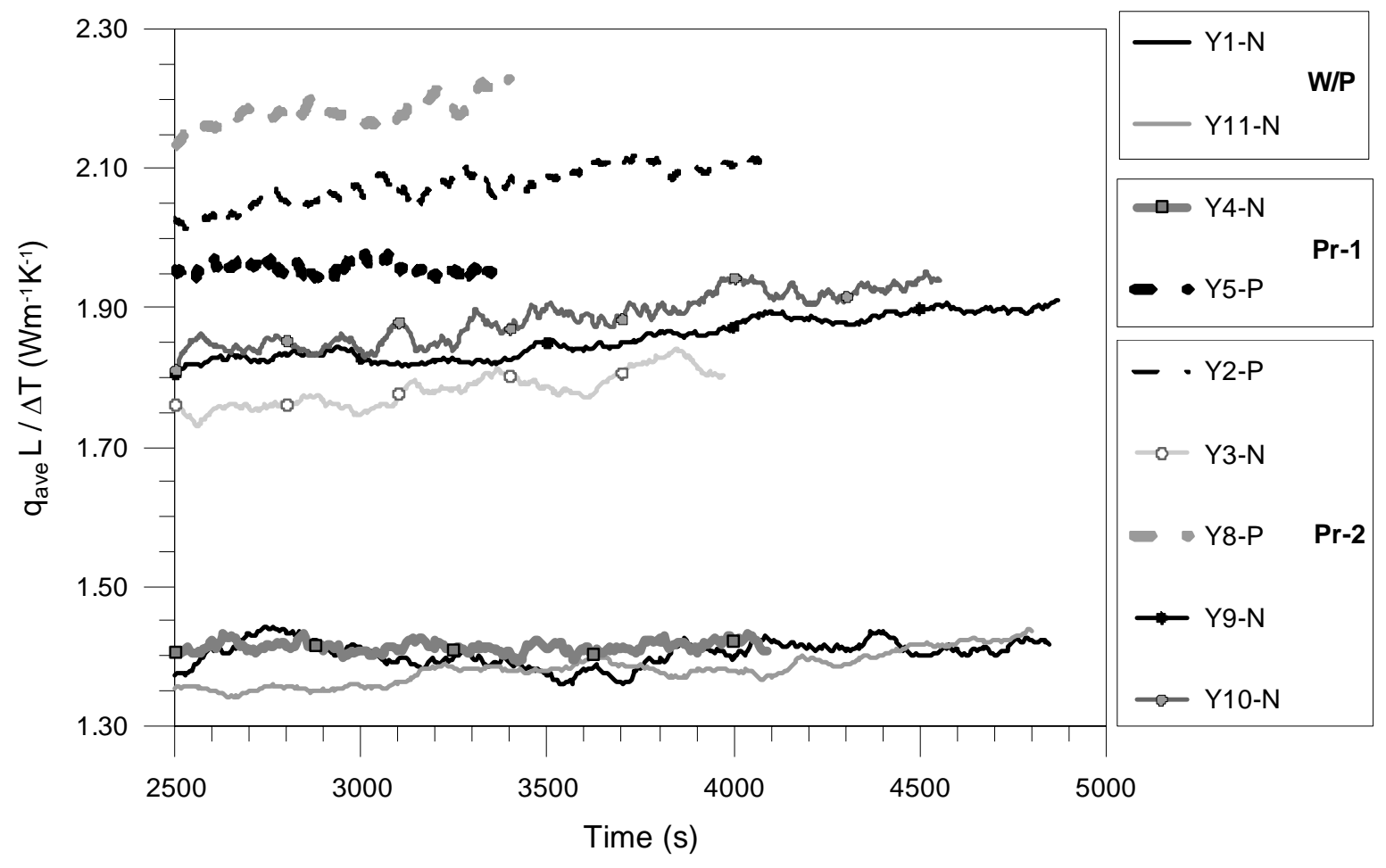


Figure 8. Influence of the degree of saturation (just before the thermal tests) on thermal conductivity. Values of thermal conductivity for two different orientations (flow parallel and orthogonal to bedding planes). Saturated thermal conductivity from back-analysis of heating cell results.

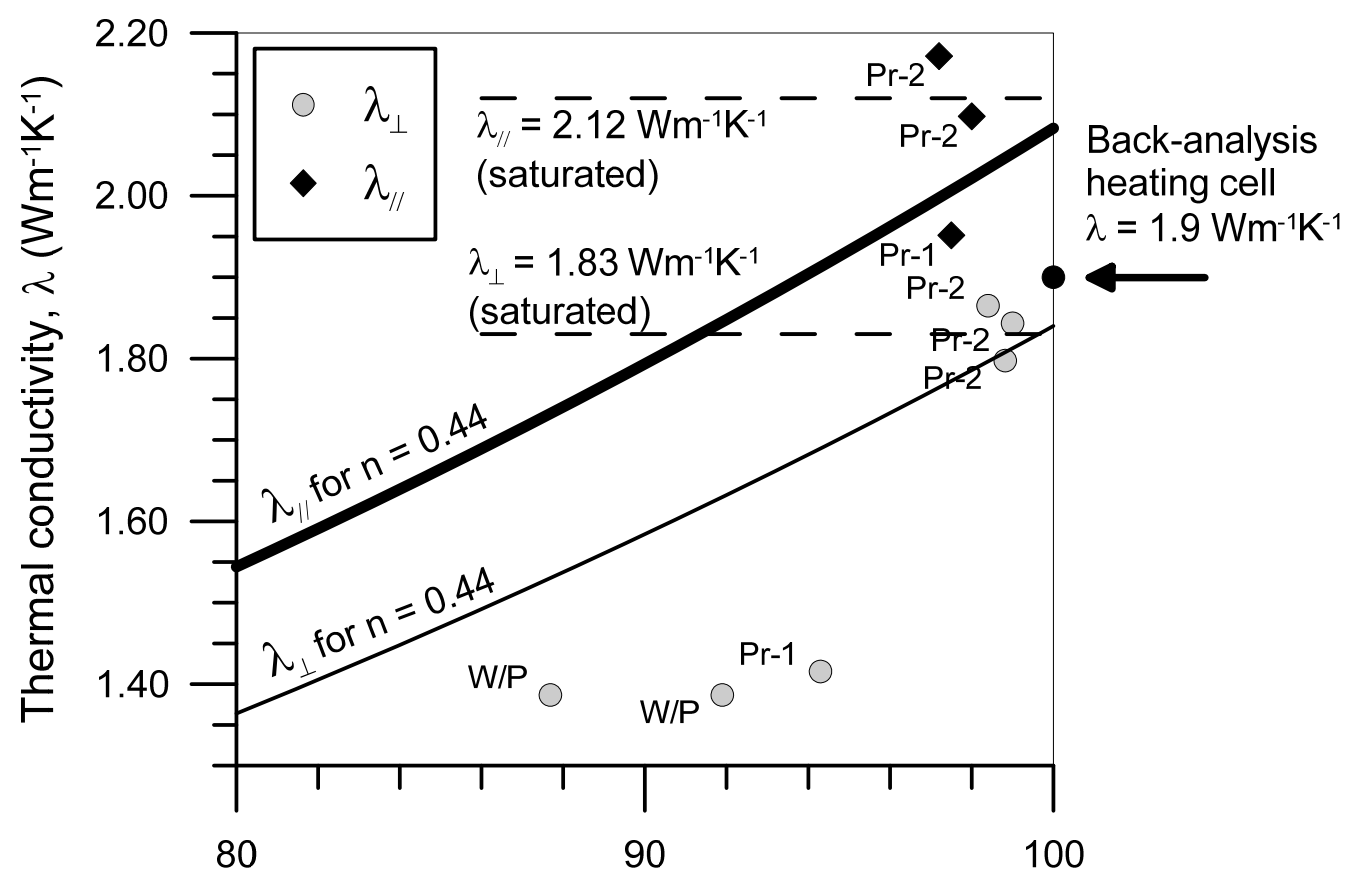

$S_{r}$ before thermal conductivity test (\%) 
Figure 9. (Left) Axi-symmetric heating cell with heater $(H)$ and thermocouples $\left(\mathrm{T}_{1}, \mathrm{~T}_{2}\right.$, $\mathrm{T}_{3}$ and $\mathrm{T}_{4}$ ) [13 - 15, 29]. (Right) Overall view of the heating cell and components (electric power supply for heater, data acquisition system and water pressure controllers connected to $u_{b}$ and $\left.u_{u}\right)$.
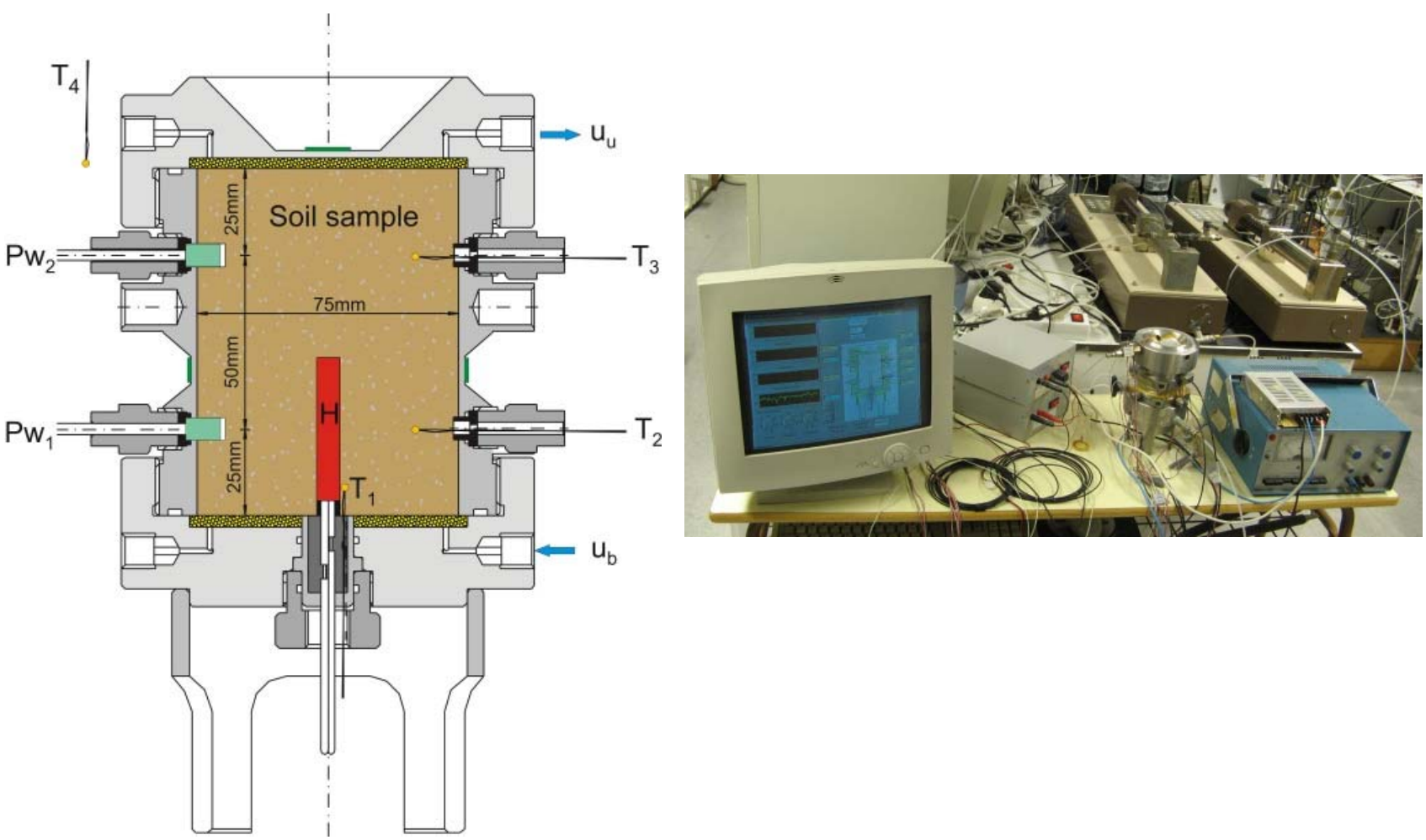
Figure 10. Heating and cooling stages. Time evolutions of temperatures at different locations - maximum heater temperature of $56^{\circ} \mathrm{C}$.

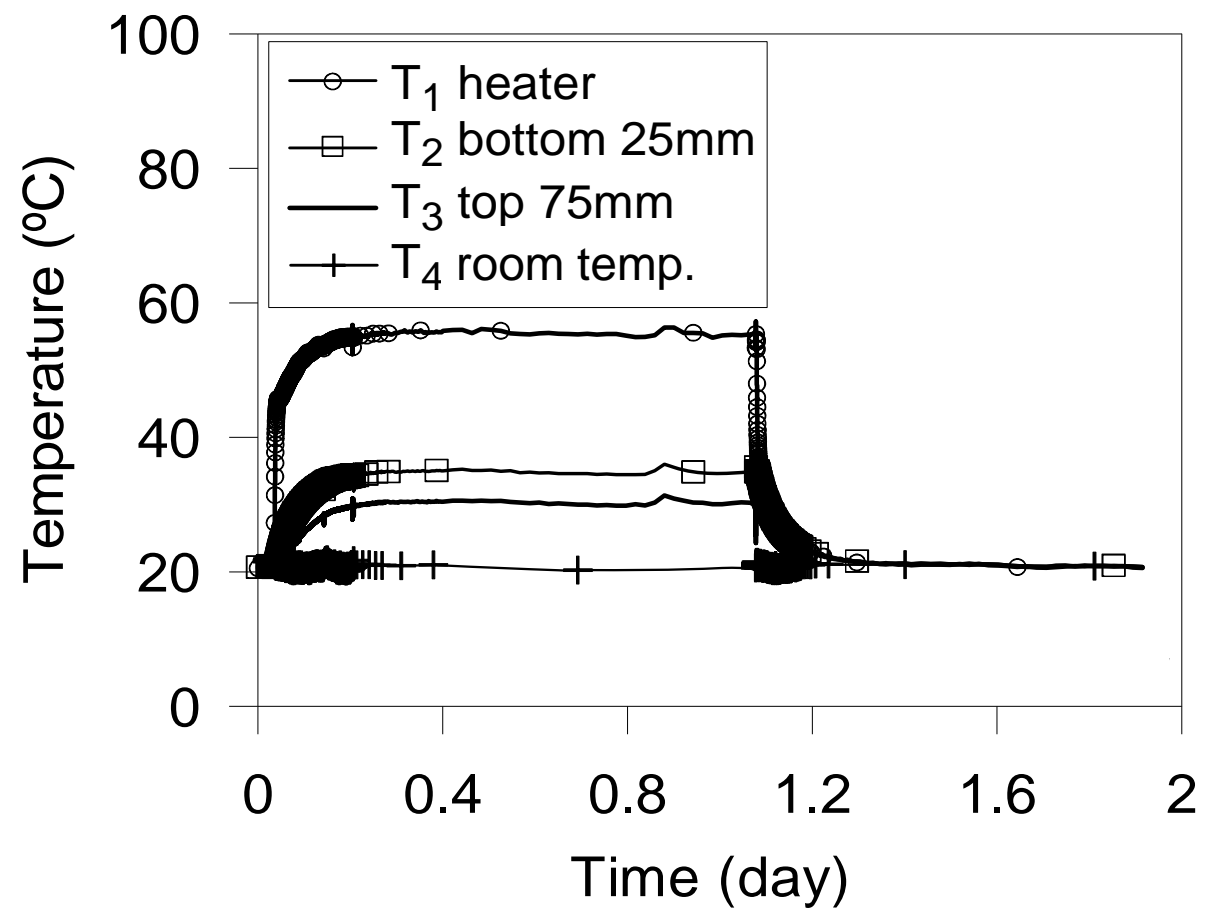


Figure 11. Geometry, different materials considered in the analysis and thermal boundary conditions.

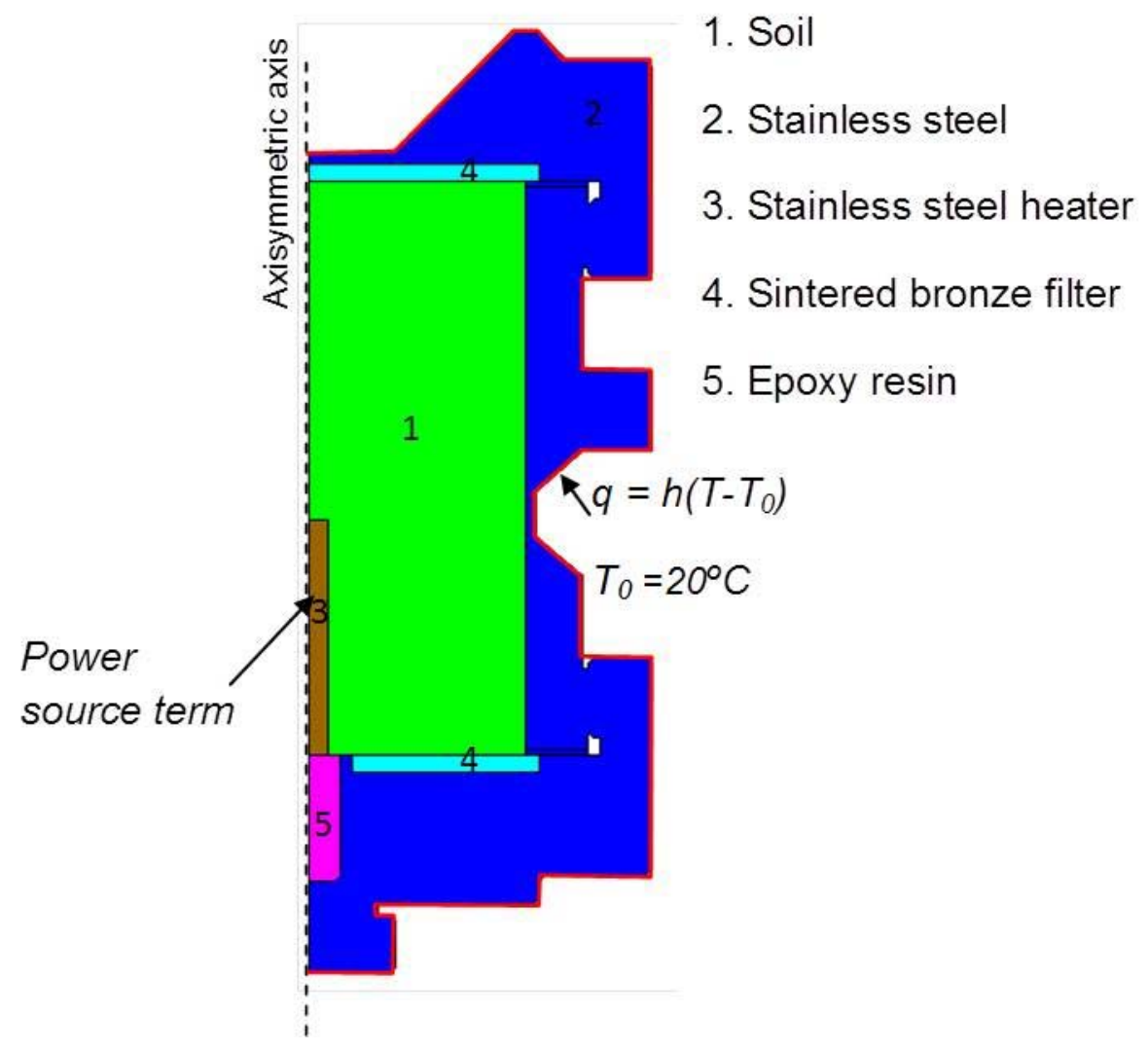


Figure 12. Three-dimensional graph showing the differences in temperature between measurements and simulations in the back-analysis of the heating pulse test. Determination of saturated thermal conductivity $\lambda$ and convective coefficient $h$.

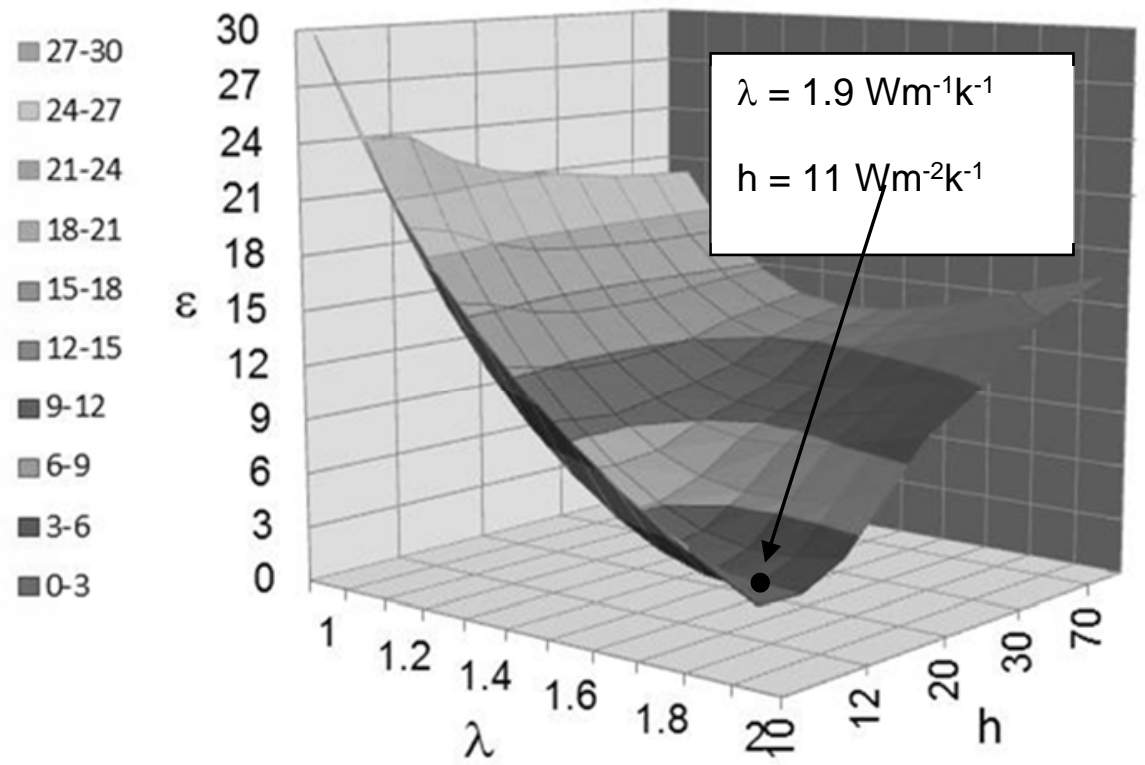


Figure 13. Heating and cooling stages at maximum heater temperature of $56^{\circ} \mathrm{C}$. Time evolutions of temperature: experimental and simulated results.

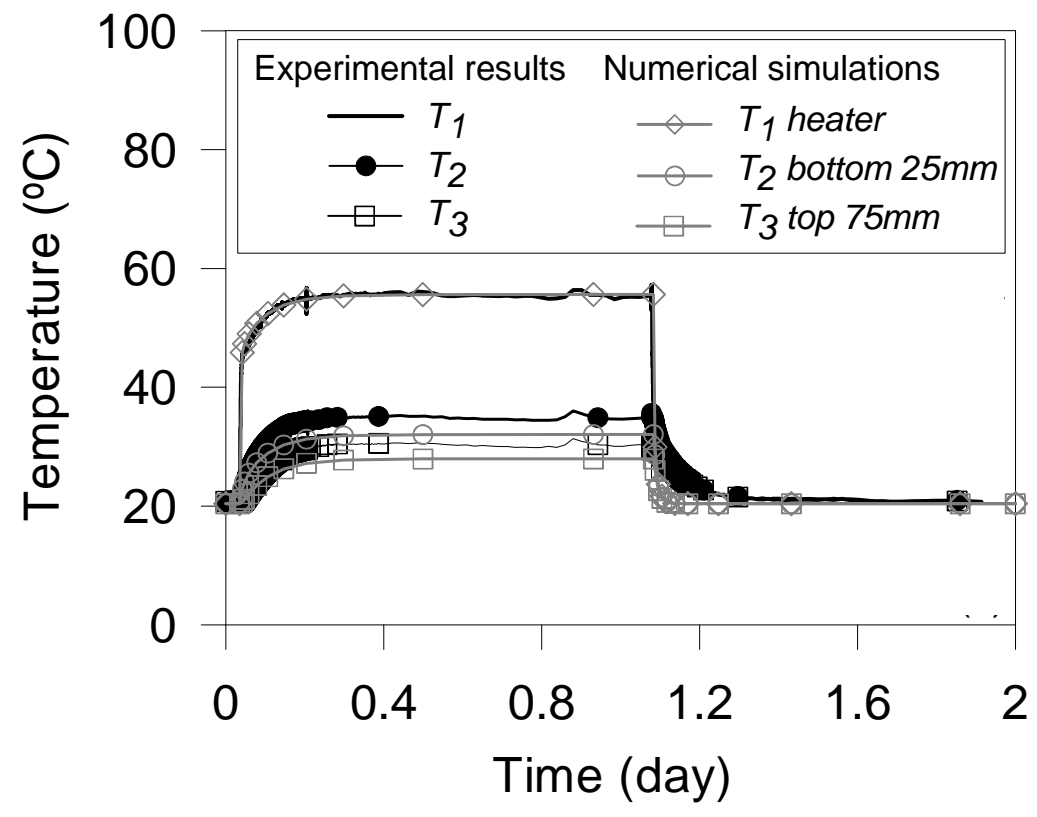

